\title{
La biblioteca de Francisco Antonio Zea en el Real Colegio de Medicina y Cirugía de Cádiz
}

\author{
Rosario Gestido del Olmo \\ Jefa de Sección de Apoyo a la Investigación y Servicios de la Biblioteca de la Universidad de \\ Cádiz \\ ORCID: https://orcid.org/0000-0002-0934-0648 \\ Ana Remón Rodríguez \\ Jefa de Sección de Colección y Patrimonio de la Biblioteca de la Universidad de Cádiz \\ ORCID: https://orcid.org/0000-0001-6354-2307
}

RESUMEN: La Biblioteca privada del Botánico Francisco Antonio Zea se inventarió e integró en la del Real Colegio de Medicina y Cirugía de Cádiz entre los años de 1808 y 1810 como resultado del decomiso de sus bienes por ser acusado de afrancesado.

Se trata de una colección de libros de corte ilustrado, cuyo tema principal es la Botánica, que su propietario utilizó para sus estudios e investigaciones sobre la flora. Los ejemplares incluidos están en línea con las bibliotecas donde inició su formación, como la de José Celestino Mutis y José Cavanilles. Parte de estos fondos se conservan en la Biblioteca de la Universidad de Cádiz.

Palabras clave: Francisco Antonio Zea (1766-1822), Biblioteca Real Colegio de Medicina y Cirugía de Cádiz (1748-1844), Bibliotecas privadas S. XVIII, Biblioteca Cortes de Cádiz (1811-1814).

\section{The Library of Francisco Antonio Zea in the Real Colegio de Medicina y Cirugía Cádiz}

ABSTRACT: The private library of the botanist Francisco Antonio Zea was integrated and inventoried into the Library of the Real Colegio de Medicina y Cirugía de Cádiz, between 1808 and 1810, as a result of the confiscation of his property after being accused of being influenced by the French "afrancesado". It is a collection of illusttrated books, whose main theme is the Botany, that its owner used for his studies and research on flora. The copies that are included are in line with the libraries where he began his training, such as José Celestino Mutis and José Cavanilles. Part of these books are kept in the library of the University of Cádiz. 
Keywords: Francisco Antonio Zea (1766-1822), Biblioteca Real Colegio de Medicina y Cirugía de Cádiz (1748-1844), Private Libraries S. XVIII, Biblioteca Cortes de Cádiz (18111814).

\section{INTRODUCCIÓN}

La investigación sobre cómo se crean las bibliotecas históricas es un interesante camino cuyo estudio nos adentra en un mundo apasionante con el libro como protagonista, en ellas se encuentra la impronta de grandes personalidades que están detrás de la creación de estas colecciones. Es el caso de la biblioteca privada de Francisco Antonio Zea, cuyos libros sirvieron para el estudio de los alumnos y profesores del Real Colegio de Cirugía, así como para el asesoramiento y apoyo de los diputados de Cortes durante el tiempo que estas permanecieron en la ciudad de Cádiz (1811-1813).

El punto de partida para la elaboración de este artículo es la revisión que realizó Ana

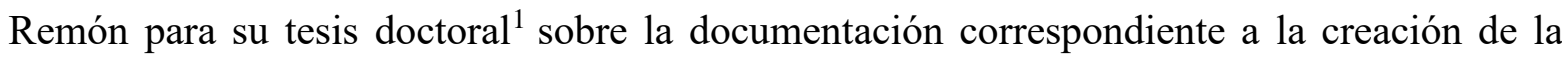
Biblioteca de Cortes, cuando estas se hallaban en la ciudad de Cádiz, y su relación con la Biblioteca del Real Colegio. Es en el intercambio de correspondencia que se estableció entre Secretarios de Cortes y el Director del Real Colegio de Cirugía de Cádiz, Carlos Francisco Ameller, en el que se le solicitan libros para crear la nueva biblioteca para los diputados, donde se menciona una colección que existe en decomiso depositada en dicho colegio perteneciente a Don N. Cea ${ }^{2}$, Director del Jardín Botánico de Madrid (Ferrer 1983, p.349). La persona que ocupaba este puesto en ese momento era Francisco Antonio Zea. Igualmente esta colección se describe por completo en uno de los inventarios del Real Colegio con la indicación de «pertenecientes a Cea» (Figura 1) ${ }^{3}$. Por tanto, estamos ante una biblioteca privada integrada en la del Real Colegio de Cirugía a principios del Siglo XIX, que aún no ha sido estudiada de forma unitaria. ${ }^{4}$

No es extraño que el lugar elegido para depositar esta colección fuera el Real Colegio de Cirugía, referente en la ciudad de Cádiz desde su creación en 1748. En esos momentos la ciudad vivía un esplendor que venía determinado por el traslado de la Casa de Contratación a la ciudad, que junto a la creación del Cuerpo de Pilotos (1748-1751) y el Observatorio de Marina (1753), posibilitará la fundación del Real Colegio de Cirugía (Cantos Casenave 2009). Este ambiente intelectual en el que proliferan los periódicos y crece el número de imprentas (Ramos Santana 2009), es un caldo de cultivo para la creación de grandes bibliotecas, como las colecciones de los conventos de San Francisco, San Agustín, Recoletos Descalzos, Capuchinos y Santo Domingo; del Palacio Episcopal, que se nutrió de los fondos de los

\footnotetext{
${ }^{1}$ Ana Remón Rodríguez dedica a este hallazgo un capítulo de su tesis doctoral, posteriormente editada y recogida en la Bibliografía de este artículo.

${ }^{2} \mathrm{La}$ convivencia entre $\mathrm{C}$ y $\mathrm{Z}$, da como resultado el uso alternativo de la misma en los escritos de la época, motivo por el cual el apellido de Francisco Antonio Zea, se escribe con Z o C arbitrariamente.

${ }^{3}$ Biblioteca Histórica UCA. Inventario perteneciente a Cea: 1777-1830?, fol. 76-80.

${ }^{4}$ Algunos de los ejemplares de la colección de Zea se han analizado en trabajos precedentes de las autoras de este artículo (Gestido del Olmo, 1994; Remón Rodríguez, 2017). 
Jesuitas después de la expulsión por Carlos III; del colegio de Guardiamarinas y la Academia de Bellas Artes (Antón Solé 1982).

Nuestro objetivo al abordar este trabajo es aportar datos sobre esta interesante colección, sus ejemplares, la personalidad de su legítimo propietario Francisco Antonio Zea y el proceso por el cual esta colección privada llegó a formar parte de la Biblioteca del Real Colegio de Cirugía, como resultado del decomiso que se aplicó a su propietario al ser encausado por afrancesado.

\section{EL PERSONAJE}

Para iniciar la aproximación al personaje hemos elegido un fragmento de una carta que Francisco Antonio Zea envía a Antonio José Cavanilles (1745-1804) y en la que da buena cuenta de una parte de su interesante vida ${ }^{5}$.

Es natural que Vm. quiera saber quién soy yo que tanto admiro sus escritos y que le ha dado tan mal rato. Yo he nacido en la Provincia de Antioquía en el Reino de Santafé. Estudiaba Leyes en aquella Universidad, en la qual era catedrático de Humanidades, quanto Mutis fue a solicitarme, o como dice el mismo en su informe al rey, a conquistarme para la Botánica. En efecto fue por su solicitud agregado a su Expedición con el destino de sucederle en la Dirección de ella y continuar sus obras. Dos años estuve en su casa instruyéndome en la Facultad, y otro pasé en una montaña solitaria haciendo excursiones botánicas. De allí fue a sacarme la calumnia de algunos enemigos, que algunas distinciones obtenidas en la Universidad y la que debí a Mutis en competencia de muchos pretendientes, me habrán conciliado. Hace dos años que estoy en Cádiz esperando a que se acuerden de hacerme justicia y restituirme a mis estudios y tarea. Entre tanto tengo la satisfacción de que las tramas de mis enemigos no me hayan privado de la amistad del D. Mutis, por más que lo intentaron (Soto Arango 1995, p.196).

Francisco Antonio Zea nació en Medellín (Colombia), el 23 de noviembre de 1766, en el seno de una familia criolla perteneciente a la nobleza colonial. Estudió en el Colegio y Seminario de Popayán y al finalizar sus estudios allí, continuará en Santa Fe, ingresando en 1786 en el Colegio de San Bartolomé. Tres años más tarde gana la cátedra de Filosofía en el mismo colegio. Su competencia profesional le llevó a ser preceptor de los hijos del Virrey José de Ezpeleta que, en 1791, a instancias de José Celestino Mutis (1732-1808), lo nombraría Segundo agregado de la Expedición Botánica de Santa Fe. En 1792 es nombrado Subdirector de la Real Expedición a Nueva Granada, instalándose en Fusagasugá (Colombia), donde se dedicó al estudio de los quinares.

El apoyo que Mutis dio a Zea será constante durante toda su vida al ponerlo bajo la tutela del botánico Antonio José de Cavanilles, que disponía de importantes contactos con los más influyentes científicos europeos (Soto Arango 1998).

\footnotetext{
${ }^{5}$ Carta de Francisco Antonio Zea a Antonio Joseph Cavanilles. Cádiz 20 de junio de 1798 (Soto Arango 1995, p. 196). 
A la vez que hacía sus observaciones para la expedición Botánica, Zea participaba en Santa Fe de Bogotá, capital del virreinato español de Nueva Granada, en la tertulia El Arcano de la Filantropía. El grupo de intelectuales, reunidos en torno al político Antonio Nariño (17651823), estaba interesado en el pensamiento ilustrado y liberal que procedía de Europa y Norteamérica, el cual repercutiría en el proceso de independencia colonial. En 1794 estos intelectuales se vieron involucrados en los sucesos de Santa Fe y en la denominada «Conspiración de los pasquines». Antonio Nariño imprimió y difundió la «Declaración de los Derechos del Hombre y del Ciudadano», aprobada en 1789 por la Asamblea Nacional de Francia y posteriormente aparecieron unos papeles anónimos considerados subversivos. A consecuencia de estos hechos se abrieron tres procesos a Nariño, Zea y Caldas, que llevan a nuestro personaje en 1796 desde su tierra a la ciudad de Cádiz con una condena de diez años. El verdadero motivo de la delación no era otro que el de mantener el dominio sobre el comercio colonial en manos hispanas (González Bueno 2002). La primera parte de su condena en Cádiz la cumplió en el castillo de San Sebastián, para pasar después a estar preso en la ciudad. Es en este período, cuando inició correspondencia y amistad con el botánico Antonio José Cavanilles 6 .

En 1799 Carlos IV expidió una Real Orden por la que mandaba poner en libertad a los condenados de la sublevación de Santa Fe. Al quedar Zea en libertad, Mutis se ofreció para costearle sus estudios por dos años en Madrid junto a Cavanilles. Sin embargo, pasado un año, este lo envió a Paris a continuar sus estudios, donde contactará con políticos y científicos europeos. Allí se ocupará, entre otras cosas de divulgar la obra de Mutis y del propio Cavanilles a través de reseñas en los periódicos y revistas.

En 1802, a su vuelta de Paris, las ideas de la Revolución Francesa habían calado en él y no duda en poner de manifiesto su marcada tendencia francófila. En 1803 viajará a Cádiz para casarse con Felipa Meilhon, hija de un comerciante francés ${ }^{7}$. En la capital dirigirá la Gaceta de Madrid y El Mercurio que utilizará para difundir su idea del Estado. En la sección política de este periódico expresó abiertamente su admiración hacia el gobierno y los científicos franceses, declarándose admirador de Napoleón al que consideraba salvador de Francia (Soto Arango 1996).

Fue nombrado segundo profesor de la Cátedra del Jardín Botánico en Madrid, para pasar posteriormente a desempeñar el puesto de Director al fallecer Cavanilles en 1804, permaneciendo en el mismo hasta 1808.

Durante toda su vida Zea combinó su actividad académica con sus inquietudes políticas. En 1807 ingresó en la Academia Nacional de Medicina y en 1808 fue nombrado Caballero de la Orden Real de España. A la vez formó parte de la Junta de Notables y participó representando a Guatemala, en la Asamblea de Bayona, entre otras actividades.

\footnotetext{
${ }^{6}$ La difusión de la Botánica no se realizaba por los canales habituales como el libro o las traducciones de obras, sino que se hizo principalmente mediante cartas e intercambio de plantas, que realizaban los propios investigadores a través de visitas, viajes, expediciones con una relación de socialización entre maestro y discípulo (Puig-Samper 1991).

${ }^{7}$ Archivo Histórico Provincial de Cádiz (AHC). Meilhon Laborda, Juan.AHPC. Protocolo 1352, fol. 240-41. 
El nuevo gobierno nombró a Zea Jefe de la Segunda División del Ministerio del Interior en 1810. La caída de José I le llevó a huir de España en 1813 y exiliarse en Paris con su familia, a la que dejó en la capital francesa para partir hacia Londres donde tuvo ocasión de contactar con un grupo de americanos partidarios de la independencia de las colonias españolas (González Bueno 2002).

Comenzó entonces una nueva etapa de lucha política para Zea vinculándose al movimiento libertador. En 1815 viajó al continente americano donde conoció a Simón Bolívar. $\mathrm{Su}$ afección y actividad política respecto a la independencia le aportó una serie de nombramientos como el de Intendente de Hacienda de los Estados de la Confederación de Nueva Granada y Venezuela en 1816, Presidente del Congreso de Angostura en 1819, y poco después fue nombrado Vicepresidente de la Gran Colombia. En esta época fundó el Semanario El correo del Orinoco, órgano oficial del gobierno independentista, donde intervendría desde el número uno (Soto Arango 1996).

Simón Bolívar le designó Ministro plenipotenciario del Gobierno colombiano viajando a Londres en 1820 con el encargo de gestionar el reconocimiento de la independencia y contratar un empréstito en Inglaterra. En 1822 volvió a repetir este viaje con el mismo objetivo. Antes de finalizar las gestiones murió en la ciudad de Bath, a los 51 años.

Zea fue un hombre práctico que desarrolló a lo largo de su vida una misma línea de pensamiento académica y política. Un amigo leal a sus amigos y protectores a los que siempre defendió, destacando el «mimetismo que tuvo siempre con las figuras del poder político y académico» (Soto Arango 1998, p. 55).

\section{LA OBRA DE FRANCISCO ANTONIO ZEA}

De la personalidad y acontecimientos que se muestran brevemente en su biografía, es fácil deducir que sus escritos se reparten entre sus dos grandes inquietudes intelectuales: la botánica y la política.

La producción de Francisco Antonio Zea se inició siendo muy joven, en 1791 con la publicación de su primer artículo Avisos de Hebephilo, en el Papel Periódico de la ciudad de Santafé, donde expone su pensamiento respecto a la educación.

Una búsqueda en los principales repertorios bibliográficos nos informa de la existencia de gran cantidad de escritos consistentes en discursos y cartas. Respecto a los primeros, en alguna ocasión llegan a publicarse como impresos en recopilatorios como Various discursos del ciudadano Francisco Antonio Zea (1825), editado en Caracas y Disertaciones y discursos de F. A. Zea sobre temas políticos, científicos, económicos y de enseñanza. También publicó el Manifiesto del ministro plenipotenciario de la Republica de Colombia á los gabinetes de Europa, (1822) editado en México o Manifiesto sobre la creación de la Republica de Colombia, (1821) impreso en Caracas, cuando era Vicepresidente de la República. Por encargo de Simón Bolívar, publicó Mediación entre España y América: discursos del ciudadano Francisco Antonio Zea, en el n. ${ }^{\circ} 7$ del Correo del Orinoco en 1818.

Respecto a la producción sobre botánica, también se recopilan y publican sus discursos, como el pronunciado en 1805 y editado ese mismo año en Madrid por la Imprenta Real, 
Discurso acerca del mérito y utilidad de la Botánica, sobre los efectos de la aplicación de la botánica para el crecimiento del país.

En 1804, mientras era director del Real Jardín Botánico, asumió la dirección del Semanario de Agricultura y Artes. En este periódico hizo una gran labor divulgativa a través de informes, discursos, memorias, y sobre todo muchas traducciones de obras francesas. Su pensamiento sobre el periódico lo deja patente en un texto muy descriptivo que plasma en su Extracto del Tratado de las Flores de Don Claudio y Don Esteban Boutelou:

Una de las grandes utilidades de los papeles periódicos es dar a conocer las obras dignas de la atención pública, analizarlas y hacer formar concepto de su mérito y de su importancia. Así se difunden las buenas ideas, se excita a hablar y discurrir, se promueve la instrucción con el estímulo de la curiosidad y poco a poco va prendiendo la brillante llama de las ciencias y de las artes que anima y hermosea la Europa (Semanario de Agricultura y Artes, n. ${ }^{\circ}$ 464. 21 Nov. 1805, p. 321).

Zea publica en los Anales de Historia Natural, (n. ${ }^{\circ} 5$ de septiembre de 1800) la Memoria sobre la quina según los principios del Sr. Mutis, lo firma como: D. Francisco Antonio Zea, botánico de la expedición de Santa Fe y discípulo del mismo Sr. Mutis, Director de ella. En esta publicación describe el Salto de Tequendama, que también se publicaría en Annalen der Physik ${ }^{8}$.

Finalmente, destacaremos la obra póstuma editada en Londres Colombia being a Geographical, Statiscal, Agricultural, and Political Account of the Country with Map and Portraits of Bolivar and F. A. Zea, etc. (1822), edición bilingüe en dos tomos, obra de propaganda revolucionaria.

\section{LA BIBLIOTECA PRIVADA DE FRANCISCO ANTONIO ZEA}

En el Siglo XVIII se crearon bibliotecas privadas que, en su mayor parte, pertenecían a altos cargos de la administración. Eran bibliotecas especializadas que respondían a la necesidad de sus propietarios de mantenerse al día profesionalmente. Por otra parte, el ambiente ilustrado de la época lleva a estos personajes a abrirse a otros campos de investigación que sirvieron para enriquecer estas bibliotecas. Este perfil se ajusta perfectamente a Francisco Antonio Zea, el cual llegó a tener un alto cargo en la administración española como director del Real Jardín Botánico de Madrid (Enciso Recio 2002). Hay que recordar que la formación académica inicial de Zea era el Derecho, siendo José Celestino Mutis quien lo atrajo a los estudios de botánica, medicina y farmacia y se preocupó de su formación mostrándole, como veremos, los libros más destacados de estas áreas de conocimiento. Igualmente su relación con Antonio Nariño, propietario de la Imprenta Patriótica, y poseedor de una gran biblioteca, le llevará a relacionarse con la Economía y procesos de manufactura, principalmente en el área de la Agronomía (Amaya y Rendón Acosta 2016).

\footnotetext{
${ }^{8}$ Wasserfall von Tequendama. Annalen der Physik, 1805, v 21 n. ${ }^{\circ}$ 10, p. 160-178. DOI del artículo: https://doi.org/10.25267/Cuad investig fondos arch UCA.2020.i2.05
}

Editorial REVISTAS | Universidad de Cádiz 
El inventario ${ }^{9}$ de las obras de Zea contiene 312 registros bibliográficos ${ }^{10}$ en 1.350 volúmenes aproximadamente. En $1777^{11}$ se amplió la Biblioteca y se elaboró un nuevo catálogo, donde se separaron algunas obras de la colección principal, sobre todo títulos pertenecientes al fondo humanístico. Al final de dicho catálogo aparece la indicación de las obras de Zea con la leyenda «Pertenecientes a Cea». ${ }^{12}$

Figura 1. Inventario perteneciente a Cea

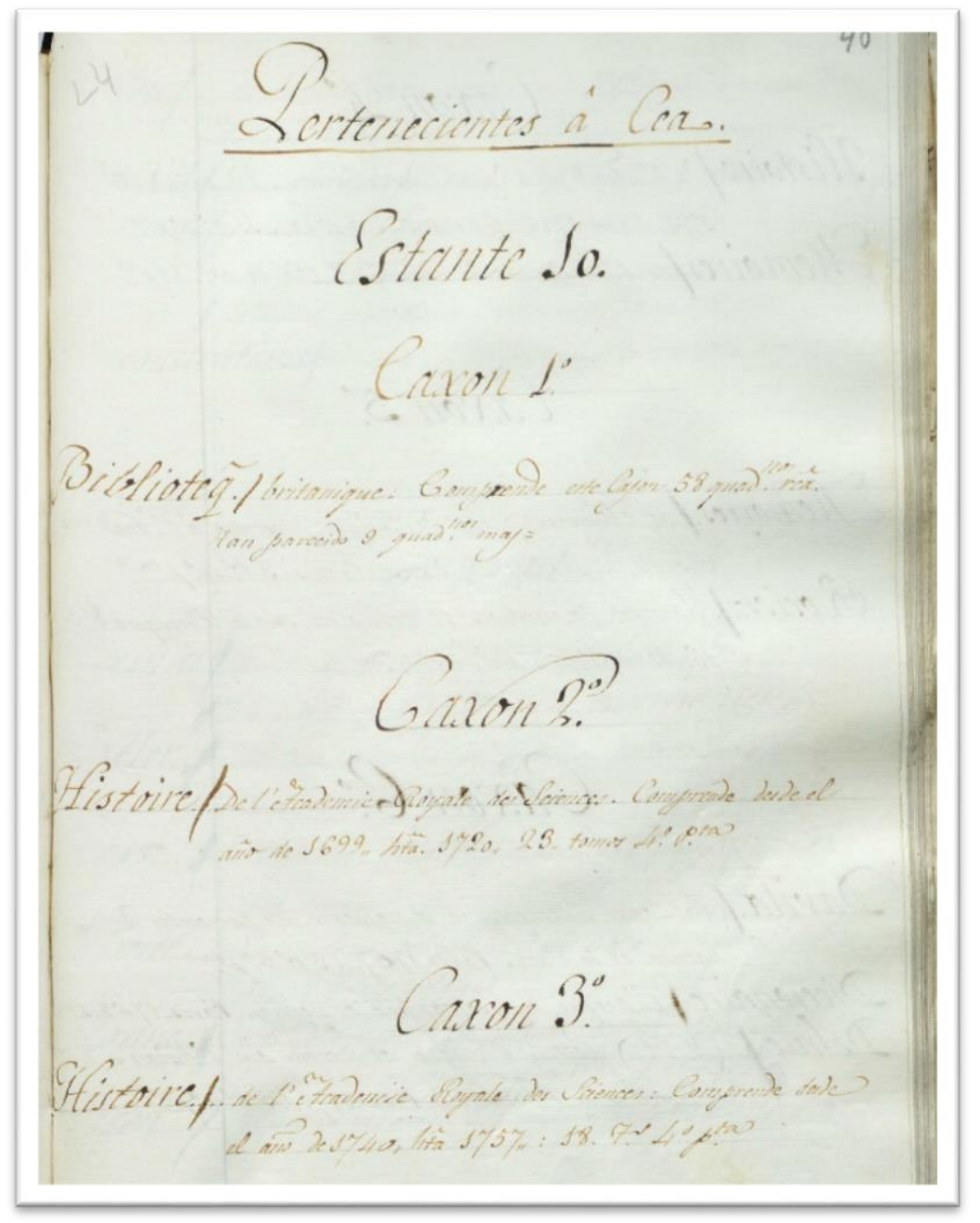

Fuente: Biblioteca Histórica UCA. Inventario perteneciente a Cea: 1777-1830?, fol. 76-80

Esta colección, que vino a incrementar los fondos bibliográficos del Real Colegio, contiene obras de diversas materias y autores que son representativos del perfil ilustrado del personaje que estudiamos y que sirvieron de apoyo para el desempeño de su actividad profesional. Como se observa en la tabla 1, las materias más representadas son Botánica, Historia Natural y Medicina.

\footnotetext{
${ }^{9}$ Biblioteca Histórica UCA. Inventario perteneciente a Cea: 1777-1830?, fol. 76-80.

${ }^{10}$ Ver Anexo Inventario extractado de Cea reconstruido del original.

${ }^{11}$ Archivo de la Universidad de la Cádiz (AUCA). Libro de cuentas. Tomo I: 1751-1780, L-3 RC, p. 648.

${ }^{12}$ Como se indica en el inventario, las obras de Zea se encontraban independientes del fondo general, entre las estanterías 10 y 20. 


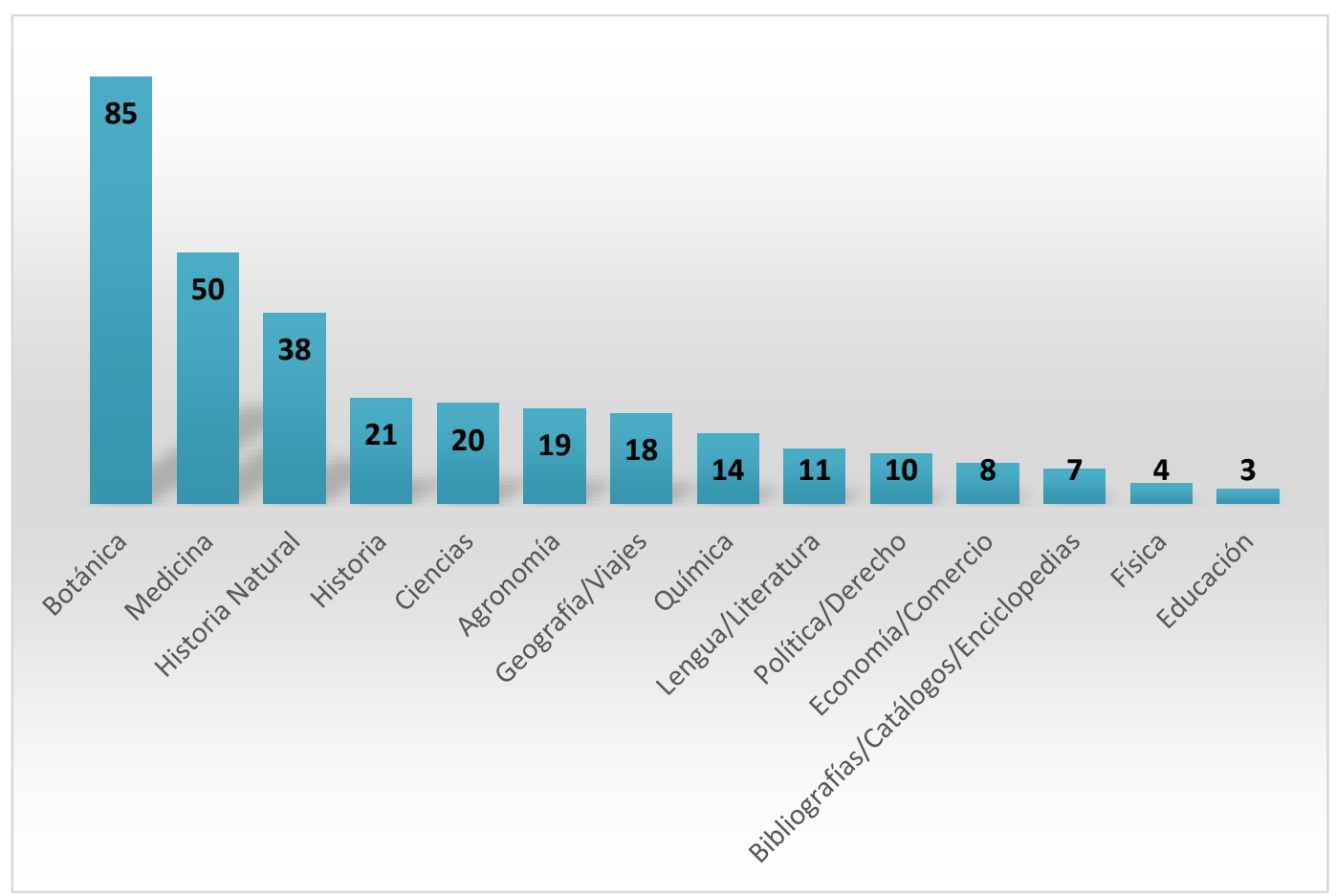

Fuente: Elaboración propia a partir del Inventario perteneciente a Cea

Desde sus inicios de formación con el maestro Mutis, el entonces aprendiz de botánico tuvo oportunidad de consultar aquellos libros que circulaban por Europa de los autores principales de Botánica, como Linneo, además de conocer en profundidad la biblioteca de Celestino Mutis, depositada en la sede de la Expedición Botánica (1783-1816). Es en este momento cuando empezó a formar su biblioteca personal, además de realizar su propio herbario (Amaya y Rendón Acosta 2016). En el catálogo de Zea nos encontramos con algunos títulos que él ya conocía porque los utilizó durante su estancia en Fusagasugá en 1793. Se trata de las siguientes obras: De Jacquin, Selectarum stirpium Americanorum Historia (1793); de Linneo, Philosophia botánica (1770) y Suplementum plantarum (1781); de Plumier, Filicetum americanarum (1703) y Description des Plantes de l'Amérique (1643).

Acostumbrado a tener acceso a las principales obras de la época sobre flora, cuando Zea es desterrado a Cádiz trasmite a Cavanilles, en carta de 20 de Junio de 1798, que en la ciudad hay escasez de libros y herbarios y pocas plantas en el Jardín Botánico (Amaya y Rendón Acosta 2017). Echa de menos estos materiales científicos porque los necesitaba para seguir con su trabajo sobre la flora de Bogotá que todavía tenía inconcluso cuando llegó a España. Por esta razón, en su colección localizamos obras relacionadas con la flora americana y la descripción de plantas en general que debió adquirir en esta época y que le resultaban imprescindibles para su trabajo, como las que indicamos a continuación:

Burman, Plantarum Americanarum (1760); de Plumier, Traité des fougères de l'Amérique (1705), y de Vahl, Eclogae Americanae seu Descriptiones plantarum praesertim (1791) (Figuras 3 y 4 ). 
Figuras 3 y 4. Vahl, Martinus Hendricksen (1744-1804). Eclogae Americanae seu Descriptiones plantarum praesertim. Copenague, 1798
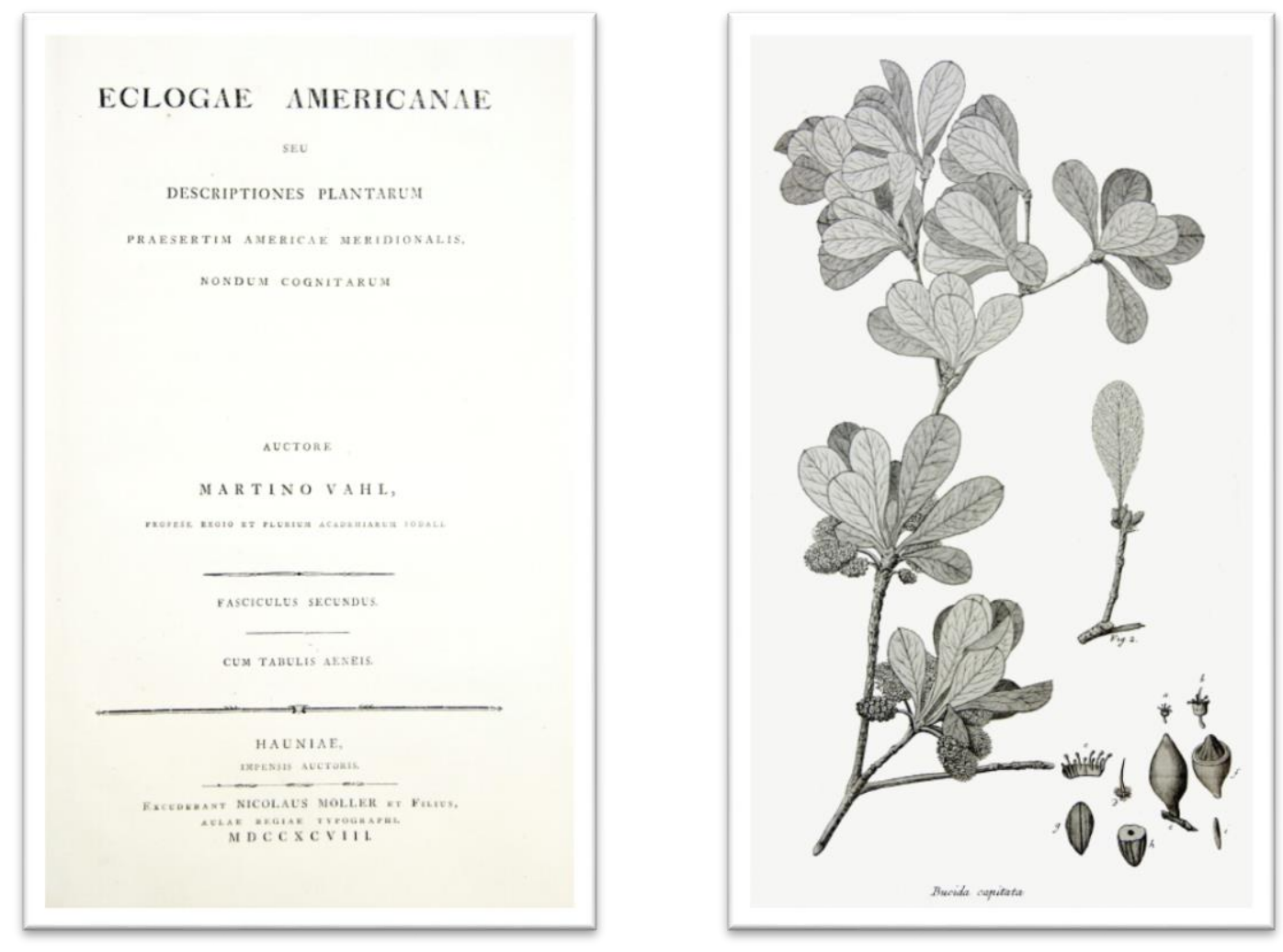

Entendemos que es durante su estancia en Cádiz cuando se hizo con una buena colección de libros que incrementaría posteriormente en su estancia en Paris, comisionado por Mutis, e incluso pudo traer material bibliográfico de la biblioteca que fue formando en su país (Amaya y Rendón Acosta 2017). Los autores que destacan con mayor número de trabajos son Duhamel, Linneo, Parmentier y Thunberg, siendo además primeras ediciones la mayor parte de ellos.

Las fechas de edición de los títulos se sitúan entre los siglos XVI y XIX, si bien el mayor número corresponde al siglo XVIII, en el que hay una alta producción de libros de Historia Natural, Botánica y Medicina. Respecto al lugar donde fueron impresas las obras, el mayor número de ellas corresponde a Paris. Otras grandes ciudades representadas serán Amsterdam, Madrid, Londres, Leiden y Venecia, a las que acompañan ciudades pequeñas pero con una producción importante como Erlangen, Gotinga, Aviñón y Copenhague (Clair 1998).

La mayoría de los ejemplares de la colección de Zea tienen ilustraciones, con un papel destacado en los libros de Botánica, Historia Natural, Viajes y Geografía. Estos grabados, en algunos casos de grandes dimensiones, pretendían un acercamiento al tamaño real de las cosas para darlas a conocer al público en general. Por sus ilustraciones podemos destacar la obra de Seba, Locupletissimi rerum naturalium thesauri, (1734-1765).

Respecto al idioma de los libros, la lengua más representada es la francesa, que se va imponiendo sobre el latín y tomando su posición en el lenguaje científico, convirtiéndose en la lengua de la Ciencia en el siglo XVIII, salvo en las obras de botánica, donde el latín se siguió utilizando hasta el siglo XIX (Riera Palmero 2013). 
En la biblioteca de Zea están representados grandes autores de botánica que pasamos a comentar. Una obra que Zea conocía porque formaba parte de la Biblioteca de Mutis que el utilizó es Voyage to the Island Madera, Barbadoes (1721) de Sloane, trabajo fundamental para la botánica de las Indias Occidentales. Contiene aproximadamente 800 nuevas especies de plantas que Sloane recolectó, en la que destaca la planta del cacao, su producción y receta para fabricarlo como alimento.

En el relato de los títulos de la biblioteca de Zea nos encontramos con dos obras del botánico francés Tournefort, Abrégé des Elémens de botanique (1745) y Histoire des plantes qui naissent aux environs de París (1725). A sus explicaciones se debe el concepto de género para las plantas. Elaboró un sistema de clasificación, de utilidad para ordenar el gran número de especies que llegaban de todas las partes del mundo. Su trabajo se fundamentó en la estructura de la corola de las flores, de los frutos y de las semillas. Su influencia será muy importante en el resto de Europa (Martín Fierro 2009).

Vaillant, con su Botanicon parisiense (1727), también se encuentra en la colección. Este autor fue el descubridor junto con Camerius del sistema sexual de las plantas. Su obra sería continuada más tarde por el naturalista, botánico y zoólogo sueco, Linneo, uno de los autores con mayor número de obras en nuestra colección, todas publicadas en latín.

Linneo pertenece al núcleo de botánicos suecos-germánicos formados en Upsala. Ejerció la carrera de médico en Estocolmo y en 1741 le concedieron la cátedra de Botánica. Consiguió uno de los mejores Jardines Botánicos del mundo. Su influencia fue enorme en el resto de botánicos por sus descubrimientos (Riera Palmero 2013). En su Philosophia Botánica (1770), estableció una taxonomía de botánicos en la que define una nueva disciplina y enumera quienes son los que la practican. En el resto de sus obras estableció de forma muy didáctica el sistema sexual de las plantas; también propuso la nomenclatura binomial. Se le considera el fundador de la moderna Taxonomía, que utilizaron muchos científicos en sus procedimientos de trabajo tanto para las plantas como para los animales (Gomis Blanco y Josa 2003). Destacamos su Systema Naturae (1744), fundamental para la botánica del siglo XVIII.

Una de las curiosidades que incluye las obras de Zea perteneciente también a Linneo, es Museum Adolphi Friderici, Regis Suecorum, in quo animalia rariora describuntur et determinantur, ... cum iconibus (1754). Es una edición de lujo que le fue encargada por el Rey de Suecia Adolf Frideriks (1710-1771) para que hiciera un catálogo de todas las especies, que él y su esposa habían coleccionado en el Gabinete de Historia Natural que tenían en palacio. Linneo pasará nueve semanas en él para realizar el catálogo. Posteriormente se realiza esta edición que no es completa y en la que se describen varios tipos de especies animales y del mundo mineral así como fósiles y plantas (González Bueno 1988).

Otro autor representado en la biblioteca de Zea es Haller, botánico, filósofo y médico, pertenece a la escuela de botánicos suizos. En 1736 obtuvo la cátedra de Botánica y Cirugía de Gotinga, donde fundó un Jardín Botánico. La colección tiene dos obras de Botánica de este autor, Enumeratio methodica stirpium Helvetiae (1742) e Historia stirpium indigenarum Helvetice inchoata (1768). En ellas realiza un estudio muy exhaustivo de la flora de Suiza, con un sistema taxonómico diferente al propuesto por Linneo (Noguera Palau 2010). 
En el inventario de la colección de Zea no puede faltar la presencia de su amigo Cavanilles. De origen valenciano, estudió Humanidades, Filosofía, Teología, Matemáticas y Física. Se trasladó a París, y permaneció allí entre 1777 y 1789, donde estudió Química y Mineralogía, y se inició en la Botánica, dibujando láminas de especies inéditas (Portolés 2013). Sus trabajos presentan un amplio abanico de técnicas naturalistas y filosóficas para registrar datos locales y detalles puntuales que luego recopilará y expondrá en su extensa obra. Formó una gran biblioteca, que a su muerte en 1801, donó al Real Jardín Botánico (Bas Martín y López Terrada 2004). Cavanilles está representado en nuestro catálogo con dos obras: Colección de papeles sobre controversias botánicas (1796) y Observations de M. L'Abbé Cavanilles sur l'article Espagne de la Nouvelle Encyclopédie (1784).

Uno de los trabajos más singulares que aporta la colección de Zea a la Biblioteca del Real Colegio es la descripción de la planta Amygdaliferum del género cariocar realizada por José Celestino Mutis, Iosephi Caelestini Mutis caryocar Amygdaliferum cusante Ant. Iosepho Cavanilles. Este trabajo es una muestra del inventario que Mutis estaba realizando en su Expedición Botánica y que envió al Conde de Floridablanca en respuesta a la Real Orden de 27 de octubre de 1789, por la cual se le piden explicaciones a Mutis sobre el retraso en el envío de resultados de sus investigaciones. Se solicitó a Gómez Ortega y Cavanilles un dictamen de la muestra enviada. Finalmente Cavanilles validará y publicará la novedad en 1797-98 (Amaya y Rendón Acosta 2016).

El naturalista Duhamel, uno de los autores más influyentes en la ciencia del siglo XVIII, está muy representado en la colección de Zea. Con un espíritu racionalista ilustrado buscaba dar base científica a las prácticas agrícolas. Realizó observaciones en la Agricultura de países europeos, describiendo las diferentes prácticas de los cultivos, siendo un gran divulgador de estos conocimientos. Proponía un nuevo sistema para practicar la agricultura y obtener mayores rendimientos económicos. Algunos de los títulos que tenía Zea son: Physica de los árboles (1772), Traité des arbres fruitiers (1768) y Traité de la conservation des grains (1753), donde plantea que otros cultivos pueden ser más rentables que el trigo (Arguemí 1993).

La agronomía es un tema de interés para Zea, pues está muy relacionado con una de las corrientes que el mismo practicó, la Fisiocracia, que tomó de las obras de Víctor Riquetti, conde de Mirabeau, uno de los fundadores de esta corriente en Francia. En la colección de Zea se encuentran dos obras de Riquetti: L'ami des hommes, ou, Traité de la population (175660) y Philosophie rurale ou Economie générale et politique de l'agriculture (1764). Estos trabajos se publicaron por fascículos, en los que el autor expone su teoría postulando que para que haya un buen funcionamiento económico no es necesaria la intervención del Estado. Para los fisiócratas únicamente la agricultura era productiva, ya que el comercio transforma, pero no produce.

En su biblioteca también queda reflejada su relación con el Real Colegio y su interés por la medicina, pues se encuentran entre sus títulos algunos de los que publicaba y vendía el propio Colegio, como Avisos sobre el methodo de recetar que deben regir en el Real Colegio (1767), el Codex formularum (1771) y la obra de Canivell i de Vila, Tratado de vendages y 
apósitos para el uso de los Reales Colegio de Cirugía (1800). ${ }^{13}$ Es indudable que su interés por la medicina se inició con la colaboración que mantuvo con Mutis para la difusión de su obra El Arcano de la Quina publicada en Cádiz en $1792 .{ }^{14}$ De ahí que en su colección existan obras de autores tan relevantes como Alibert, Bell y Cullen entre otros.

La colección cuenta con algunas enciclopedias, entre las más importantes, la Encyclópedie, ou Dictionnaire raisonné des sciences, des arts et des métiers, realizada por el empeño de Diderot y D'Alembert. Considerada la primera enciclopedia moderna, en 182 volúmenes, está ordenada alfabéticamente y contiene preciosas ilustraciones.

\section{El PROCESO DE EXPROPIACIÓN DE LOS BIENES DE FRANCISCO ANTONIO ZEA}

Como hemos visto en el apartado correspondiente, las inquietudes políticas de Francisco Antonio Zea y su pensamiento afrancesado, gestado desde los tiempos de la tertulia de $E l$ Arcano de la filantropía (González Bueno 2002) lo llevan, en Julio de 1808, a ponerse a disposición del gobierno de José I, sufriendo por esta causa el castigo y la represión que se puso en marcha unos días después de iniciado su reinado. Una de las primeras medidas que se tomaron contra los afectos al nuevo monarca fue el embargo y la confiscación de bienes.

La documentación localizada al respecto nos revela que el 19 de agosto de 1808 el Consejo Supremo de Castilla comisionó a don Ignacio Martínez de Villela y Don Benito Arias de Prada para «el embargo y secuestro de todos los bienes de cualquier clase o condición de dentro o fuera de Madrid [...] y todas las demás personas sin distinción alguna que hayan salido de esta capital y pueblos del Reyno para acompañar a Josef Napoleón o con motivo de la retirada de las tropas francesas disponiendo que en las casas y sitios donde se custodiasen los bienes se coloquen las armas de S.M». En el documento se enumeran una serie de personajes entre los cuales se encuentra Francisco Antonio Zea ${ }^{15}$.

En el expediente de su causa, ${ }^{16}$ iniciada en Agosto de 1808 (Figura 5), se describe todo el proceso que se lleva a cabo para encausar a Francisco Antonio Zea y proceder a la expropiación de sus bienes. Son interrogados todos sus allegados sobre su paradero y su relación con individuos franceses que frecuentaban su casa para intercambiar información ${ }^{17}$. Es una constante en el proceso la pregunta de «donde está» y «qué se llevó consigo», insistiendo todos los testigos y su esposa Felipa Meilhón que sólo llevaba una maleta.

\footnotetext{
${ }^{13}$ Archivo de la Universidad de Cádiz (AUCA). Libro de cuentas del Real Colegio de Cirugía de la Armada, 1792-1836. Año 1810, L-46 RC, p. 166.

${ }^{14}$ En el estudio se analizan las propiedades medicinales de cuatro especies de quina. Es una obra más médica que botánica.

${ }^{15}$ Expediente relativo a las órdenes comunicadas por el Supremo Consejo de Castilla, a la Comisión creada para proceder al embargo y secuestro de todos los bienes de aquellas personas que hubieran abandonado la Corte y los pueblos del reino de España para acompañar a José Bonaparte. Archivo Histórico Nacional (AHN), CONSEJOS, 9395, Exp. 85.

${ }^{16}$ Expediente relativo a la causa incoada por orden del Real y Supremo Consejo de Castilla contra Francisco Antonio Zea, director del Jardín Botánico de Madrid. Archivo Histórico Nacional, (AHN), ES.28079.AHN/1.1.43.2.1//CONSEJOS, 9395, Exp. 86, 1808-09-30/1808-11-30.

${ }^{17}$ Recibía documentos franceses para traducir que, posiblemente se publicarían en el Semanario de Agricultura y Artes que dirigió Zea desde 1804 hasta 1808. 
En la causa que se le incoa no se indican qué bienes se le decomisan, pero es evidente que en su domicilio de Madrid de la calle del Príncipe no encuentran gran cosa y que el acusado huye con sólo una maleta. Sin embargo, se le incautó su biblioteca privada, ya que tenemos la evidencia de que dichos fondos están depositados en el Real Colegio de Cirugía de Cádiz en 1810 porque Bartolomé José Gallardo, diputado de Cortes e inminente bibliotecario, había visitado esta institución en diciembre del mismo año. Fruto de esta visita es el catálogo que realizó el 24 de enero de $1811^{18}$, en el que presentaba una relación de obras necesarias para el apoyo a los diputados, donde ya se describían títulos concretos de la colección de Francisco Antonio Zea. Será el 17 de Febrero del mismo año cuando mediante carta solicitará al director del Real Colegio de Cirugía, Francisco Ameller, los Índices de las colecciones de Marina y el catálogo de Zea (Ferrer 1983, p.350 y ss).

Habiéndose de proceder desde luego, a la designación y entresaca de los volúmenes que han de constituir la Biblioteca de Cortes conforme a lo decretado por S.M., se hace necesario tener a la vista el catálogo de la colección denominada Cea, y el índice metódico de la Marina, el cual, en caso de no haber llegado aún a manos de V.S., espero se servirá indicarme la persona en cuyo poder deba o pueda existir.

El 19 de marzo de 1811, según el Diario de Sesiones de las Cortes de Cádiz se vuelve a insistir en la recuperación de estas obras para la Biblioteca de las Cortes:

La comisión de la Biblioteca de Cortes, vista la exposición del bibliotecario de S. M., D. Bartolomé José Gallardo, con los documentos que acompaña, y la representación de los señores director y maestros consultores del Real Colegio de Medicina y Cirugía de esta plaza de Cádiz, fue de parecer que estos últimos, acreditando mejor que hasta ahora el celo e interés por la causa pública, de que tanto blasonan, entreguen inmediatamente al referido Gallardo los libros expresados en el catálogo que presenta pertenecientes a la biblioteca de marina y a la de D. Francisco Cea, adicto al Gobierno intruso, destinados por S M para la de Cortes, y depositados en dicho Real Colegio; y que se reencargue al director del mismo que responda de1 catálogo de los libros y cartas de marina, sobre lo cual se ha oficiado varias veces, sin que haya dado contestación ${ }^{19}$

Aunque la petición de salida de estas obras provocó una respuesta unánime de rechazo por parte de la Junta de Profesores del Colegio, ${ }^{20}$ finalmente los libros seleccionados salieron del Real Colegio de Cirugía para formar parte de la Biblioteca de Cortes, siendo entregadas a Gallardo por el bibliotecario Juan Rodríguez Jaén ${ }^{21}$, el 28 de marzo de 1811 a las cuatro de la tarde.

Cuando ocurren estos hechos Zea se encuentra huido, pero entendemos que sus bienes estaban en la ciudad de $\mathrm{Cádiz}^{22}$, donde sin duda seguía manteniendo contactos y familiares.

\footnotetext{
${ }^{18}$ Catálogo de algunos libros depositados en el Colegio de Cirugía de Cádiz, que se consideraron de utilidad para el uso de las Cortes, año 1811. Archivo de las Cortes (España). Leg. 49, exp. 189, n. ${ }^{\circ}$ 101, (copia del catálogo cedida por Alberto Ramos Santana).

${ }^{19}$ Diario de Sesiones. Legislatura 1810-1813. Cortes de Cádiz. 19-03-1811. N. ${ }^{\text {171 }}$, p. 716.

${ }^{20}$ Archivo de la Universidad de la Cádiz (AUCA). Correspondencia Real Colegio de Cirugía. Caja 60-1 RC.

${ }^{21}$ Archivo de la Universidad de la Cádiz (AUCA). Correspondencia del Real Colegio. Caja 59-8 RC.

${ }^{22}$ Habitó primero en la calle Portal de Paños y luego en la calle del Fideo, n. ${ }^{\circ}$ 18, actualmente llamada calle Enrique de las Marinas (Soto Arango 1995).
} 
No se ha podido datar el momento en el que estos fondos ingresan en el Real Colegio, ya que no ha sido localizada documentación que evidencie este hecho; sin embargo, pensamos que pudo ser entre 1808, cuando se inicia el expediente del decomiso, y 1810, según las evidencias observadas.

En 1814, al cerrar definitivamente la biblioteca de Cortes en Cádiz, el Secretario de Despacho de Marina reclamará la devolución de estas obras pertenecientes a Marina y a la Colección de Cea que habían sido entresacados de la Biblioteca del Real Colegio de Cirugía para formar la biblioteca de Cortes. A lo que la regencia responde y manifiesta: "la materia es necesaria para los oficiales de la Armada y de ahí el consejo de que las Cortes devolvieran aquellos libros, excepto los de Cea que no pertenecen al cuerpo" (Salavert 1983, p.42). Sin embargo, hemos comprobado que en la lista de devolución de los libros de Cortes ${ }^{23}$ aparecen 170 libros pertenecientes a la colección de Zea que se incorporaron de nuevo a la Biblioteca del Real Colegio.

Con fecha de 23 de Junio de 1814 se realizó el Acta de devolución de la Biblioteca de Cortes al Real Colegio de Cirugía (Salavert 1983). Un año más tarde constatamos una anotación en el libro de cuentas del Real Colegio que nos indica que estos libros fueron devueltos al Real Colegio: «Por la conducción de libros y estantes de la biblioteca de las Cortes, al Colegio 78 reales de vellón, y por un escribiente que copio la relación de los libros recibidos de la Marina, pedida por el capitán general, 60 reales de vellón». ${ }^{24}$

Figura 5. Expediente relativo a la causa incoada por orden del Real y Supremo Consejo de Castilla contra Francisco Antonio Zea, director del Jardín Botánico de Madrid

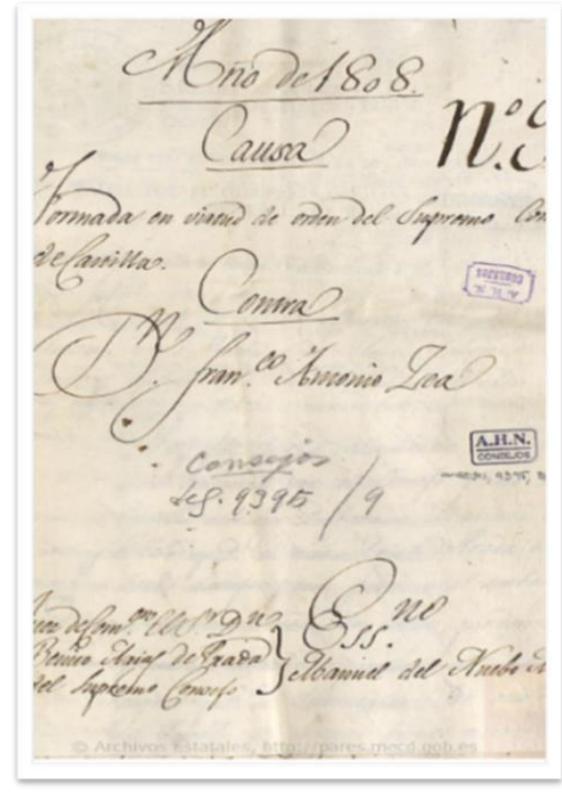

Fuente: Archivo Histórico Nacional, ES.28079.AHN/1.1.43.2.1//CONSEJOS,9395, Exp.86

\footnotetext{
${ }^{23}$ Archivo del Congreso de los Diputados (ACD). Índice hallado en San Felipe Neri, de la Biblioteca primitiva de Cortes establecida en Cádiz en 1811, que fue suprimida y agregada al Colegio Médico de Cirugía de Cádiz (1814). ES.28079 A.C.D.//P-01-000049-0194.

${ }^{24}$ Archivo de la Universidad de la Cádiz (AUCA). Libro de cuentas del Real Colegio de Cirugía de la Armada 1792-1836. Año 1815, p. 205.

DOI del artículo:

https://doi.org/10.25267/Cuad investig fondos arch UCA.2020.i2.05

Editorial

REVISTAS | Universidad de Cádiz
} 


\section{CONCLUSIÓN}

La Biblioteca del Real Colegio de Cirugía se compone de colecciones que fueron ingresando a lo largo de la vida de la Institución. Una de las de mayor importancia por su contenido es la biblioteca privada de Francisco Antonio Zea. Las circunstancias que le toco vivir llevaron a este botánico de su Colombia natal a la ciudad de Cádiz. De nuestro estudio se deduce que la Biblioteca privada de Francisco Antonio Zea se formó durante su estancia en España, y que su localización sería la ciudad de Cádiz, pues se integró a los fondos de la Biblioteca del Real Colegio de Medicina y Cirugía de Cádiz entre los años de 1808 y 1810 como resultado del decomiso de sus bienes al ser acusado de afrancesado.

La colección, registrada en los inventarios de la Biblioteca del Real Colegio, constaba de 312 obras de las cuales un $40 \%$ permanecen actualmente en la Biblioteca de la Universidad de Cádiz; el resto se pudieron incorporar a la biblioteca de Marina o han desaparecido con el paso del tiempo.

Se trata de una Biblioteca ilustrada, siendo la mayor parte de sus obras de autores del siglo XVIII, coetáneos a su propietario. La biblioteca contenía libros de todas las materias y especialmente de Historia Natural, Medicina y sobre todo Botánica. Es una biblioteca eminentemente profesional que Zea formó en la línea de las bibliotecas de sus maestros José Celestino Mutis o José Cavanilles con las que se inició en su profesión.

Finalmente hay que destacar que la calidad de esta colección hizo que, con motivo del establecimiento de la Biblioteca de las Cortes en Cádiz, en 1811, parte de los fondos de Zea se trasladaran a la misma por intervención de su bibliotecario, Bartolomé José Gallardo. Estos libros sirvieron de apoyo a los diputados de Cortes mientras esta permaneció en la ciudad de Cádiz.

\section{BIBLIOGRAFÍA}

AmAYA, J.A. y ReNdón AcostA, J. L., 2016. La formación de Hebephilo naturalista, 17911794. Fronteras de la Historia, vol. 21, no. 2, pp. 104-131. ISSN 2027-4688.

AmAYA, J.A. y RENDÓn AcostA, J. L., 2017. Veintiuna líneas que cambiaron la Historia de la Ciencia en Nueva Granada y su relación con la Metrópoli. Análisis de la descripción de la Flora de Bogotá de Francisco Antonio Zea a Antonio José Cavanilles. Historia crítica, no. 63, pp. 33-52. ISSN 0121-1617.

Antón SolÉ, P., 1982. Biblioteca y bibliófilos gaditanos. Archivo Hispalense, no. 200, pp. 41-57. ISSN 0210-4067.

ARGUEMÍ, L., 1993. La revolución agrícola en España. Madrid: Akal.

BAs MARTín, N. y LóPez TerradA, M. L., 2004. Una aproximación a la biblioteca del botánico valenciano Antonio José Cavanilles (1745-1804). Segundo centenario de la muerte de un gran botánico. Valencia: Real Sociedad Económica de Amigos del País de Valencia, pp. 201-285. ISBN 978-84-4823-874-2.

Cantos Casenave, M. C., 2009. Cádiz enclave militar, ciudad cultural. A modo de Introducción. Estudios superiores en Cádiz desde 1748. Armada e Ilustración. Cádiz: 
Publicaciones de Defensa;Servicio de Publicaciones de la Universidad, pp. 15-23. ISBN 978-84-9828-245-0.

ClaIR, C., 1998. Historia de la imprenta en Europa. Madrid: Ollero\&Ramos. ISBN 978-847895-109-3.

ENCISO RECIO, L. M., 2002. Barroco e ilustración en las bibliotecas privadas españolas del Siglo XVIII. Madrid: Real Academia de la Historia. ISBN 84-8951-201-9.

Ferrer, D., 1983. Historia del Real Colegio de Cirugía de Cádiz. Cádiz: Servicio de Publicaciones de la Universidad.

Gestido Del Olmo, R., 1994. Una biblioteca ilustrada gaditana. Los fondos bibliográficos humanísticos del Real Colegio de Cirugía de la Armada. Cádiz: Servicio de Publicaciones de la Universidad. ISBN 84-7786-178-1.

Gomis Blanco, A. y JOSA, J., 2003. Veinticinco años de historia de la Biología en España (1977-2002). Llul, vol. 26, no. 55, pp. 109-156. ISSN 0210-8615.

GonZÁlez Bueno, A., 1988. Los sistemas de clasificación de los seres vivos. Madrid: Akal. ISBN 84-460-0800-9.

GonzÁlez Bueno, A., 2002. Tres botánicos de la Ilustración: Gómez Ortega, Zea, Cavanilles: la ciencia al servicio del poder. Madrid: Nivola. ISBN 84-451-2342-4.

Martín Fierro, P., 2009. Semblanza de un sabio:José Celestino Mutis. Entre la Ciencia y la aventura. Cádiz: Quorum, pp. 27-60. ISBN 978-84-92581-09-2.

Noguera Palau, J., 2010. Albrecht von Haller (Berna, 1708-Berna, 1777). Archivos de la Sociedad Española de Oftalmología, vol. 85, no. 2, pp. 88-90. ISSN 1989-7286.

PortolÉs, M., 2013. La obra de Cavanilles en «La Económica». Antonio José Cavanilles (1745-1804): segundo centenario de la muerte de un gran botánico. Valencia: Real Sociedad Económica de Amigos del País, pp. 4-5. ISBN 9781604138795.

PUIG-SAMPER, M. A., 1991. Las expediciones científicas durante el siglo XVIII. Madrid: Akal. ISBN 978-84-760-0740-2.

Ramos Santana, A., 2009. Una aproximación a la vida cultural en el Cádiz de las Cortes. Estudios superiores en Cádiz desde 1748. Armada e Ilustración. Cádiz: Publicaciones de Defensa; Servicio de Publicaciones de la Universidad, pp. 25-41. ISBN 978-849828-245-0.

REMÓn RodrígueZ, A., 2017. El libro médico-científico en la Biblioteca del Real Colegio de Cirugía de Cádiz (1748-1844). Cádiz: Editorial UCA. ISBN 978-84-9828-643-4.

Riera Palmero, J., 2013. Nuestro siglo XVIII: libros, médicos y traductores. Anales de la Real Academia de Cirugía de Valladolid, vol. 50, pp. 215-243. ISSN 0210-6523.

SAlaVert, V., 1983. La Biblioteca del Congreso de los Diputados: notas para su historia (1811-1836). Madrid: Congreso de los Diputados. ISBN 978-84-500-8936-3.

Soto Arango, D. E., 1995. Cavanilles y Zea: una amistad político-científica. Asclepio, vol. 47, no. 1, pp. 169-196. ISSN 0210-4466.

Soto ArAngo, D. E., 1996. Francisco Antonio Zea: periodista, botánico y político. Asclepio, vol. 48, no. 1, pp. 123-144. ISSN 0210-4466.

Soto ARANGO, D. E., 1998. Francisco Antonio Zea y la enseñanza de la agricultura en el Real Jardín Botánico de Madrid. Historia crítica, no. 16, pp. 43-60. ISSN 0121-1617. 
ZEA, F. A. 1805. Extracto del Tratado de las Flores de Don Claudio y Don Esteban Boutelou. Semanario de Agricultura y Artes, n. ${ }^{\circ} 464.21$ nov. 1805, p. 321-328.

\section{FUENTES DOCUMENTALES}

Archivo de la Universidad de la Cádiz (AUCA). Libro de cuentas del Real Colegio de Cirugía 1792-1836. Año 1815, p. 205. L-46 RC.

Archivo de la Universidad de la Cádiz (AUCA). Correspondencia Real Colegio de Cirugía. Caja 60-1 RC, 1 hoja.

Archivo de la Universidad de la Cádiz (AUCA). Juan Rodríguez Jaén. Sig. C-59-8 RC

Archivo de la Universidad de la Cádiz (AUCA). Libro de cuentas. [Tomo I]: 1751-1780, p. 648. L-44 RC.

Archivo del Congreso de los Diputados (ACD). Catálogo de algunos libros depositados en el Colegio de Cirugía de Cádiz, que se consideraron de utilidad para el uso de las Cortes, año 1811. Leg. 49, exp. 189, n. ${ }^{\circ} 101$.

Archivo del Congreso de los Diputados (ACD). Índice hallado en San Felipe Neri, de la Biblioteca primitiva de Cortes establecida en Cádiz en 1811, que fue suprimida y agregada al Colegio Médico de Cirugía de Cádiz. ES.28079 A.C.D.//P-01-000049-0194.

Archivo Histórico Nacional (AHN). Expediente relativo a la causa incoada por orden del Real y Supremo Consejo de Castilla contra Francisco Antonio Zea, director del Jardín Botánico de Madrid. ES.28079.AHN/1.1.43.2.1//CONSEJOS, 9395, Exp.86:1808-0930/1808-11-30.

Archivo Histórico Nacional (AHN). Expediente relativo a las órdenes comunicadas por el Supremo Consejo de Castilla, a la Comisión creada para proceder al embargo y secuestro de todos los bienes de aquellas personas que hubieran abandonado la Corte y los pueblos del reino de España para acompañar a José Bonaparte. Consejos, 9395, Exp. 85.

Archivo Histórico Provincial de Cádiz (AHC). Meilhon Laborda, Juan. AHPC. Protocolo 1352, fol. 240-41.

Biblioteca Histórica UCA. Inventario perteneciente a Cea: [1777-1830?], L4, fol. 76-80. 
ANEXO. Inventario extractado de Cea reconstruido del original

\begin{tabular}{|c|c|c|c|c|}
\hline AUTOR & TITULO & LUGAR & AÑO & MATERIAS \\
\hline \multirow{3}{*}{$\begin{array}{l}\text { Académie Royale des } \\
\text { Sciences (France) }\end{array}$} & $\begin{array}{l}\text { Table alphabetique des matieres } \\
\text { contenes dans l'histoire les } \\
\text { mémoires de l'academie royale } \\
\text { des sciences }\end{array}$ & Paris & $1686-$ & Ciencias \\
\hline & Machines et inventions & París & 1735 & Ciencias \\
\hline & $\begin{array}{l}\text { Mémoire de mathematiques et de } \\
\text { physique }\end{array}$ & París & $1750-86$ & Ciencias \\
\hline $\begin{array}{l}\text { Ahmad ibn Mohammed } \\
\text { ibn Kathir, Al Farghani } \\
\text { (Alfraga) }\end{array}$ & Elementa astronomica & $\begin{array}{l}\text { Ámsterda } \\
\mathrm{m}\end{array}$ & 1669 & Ciencias \\
\hline $\begin{array}{l}\text { Alberti di Villanuova, } \\
\text { Francesco d' (1737-1801) }\end{array}$ & $\begin{array}{l}\text { Nouveau dictionnaire françoise- } \\
\text { italien }\end{array}$ & Marsella & 1796 & $\begin{array}{l}\text { Lengua } \\
\text { Literatura }\end{array}$ \\
\hline \multirow[b]{2}{*}{$\begin{array}{l}\text { Alibert, Jean-Louis- } \\
\text { Marie (1768-1837) }\end{array}$} & $\begin{array}{l}\text { Eloge historique de Lazare } \\
\text { Spallanzani }\end{array}$ & París & 1800 & Medicina \\
\hline & $\begin{array}{l}\text { Dissertation sur les fièvres } \\
\text { pernicieuses, ou ataxiques } \\
\text { intermittentes }\end{array}$ & París & 1799 & Medicina \\
\hline $\begin{array}{l}\text { Alpini, Proper (1553- } \\
\text { 1617) }\end{array}$ & Medicina aegyptiorum Accedunt & Lyon & 1719 & Medicina \\
\hline \multirow[t]{2}{*}{$\begin{array}{l}\text { Alyon, Pierre Philippe } \\
\text { (1758-1816) }\end{array}$} & $\begin{array}{l}\text { Cours élémentaire de chimie } \\
\text { théorique et pratique }\end{array}$ & París & 1787 & Química \\
\hline & $\begin{array}{l}\text { Arte de recetar. Avisos sobre el } \\
\text { methodo de recetar que se debe } \\
\text { utilizar en el Real Colegio }\end{array}$ & $\begin{array}{l}\text { Barcelon } \\
\text { a }\end{array}$ & 1767 & Medicina \\
\hline $\begin{array}{l}\text { Aublet, Jean Baptiste } \\
\text { Christophe Fusée (1720- } \\
\text { 1778) }\end{array}$ & $\begin{array}{l}\text { Histoire des plantes de la Guiane } \\
\text { Françoise }\end{array}$ & Londres & 1775 & Botánica \\
\hline $\begin{array}{l}\text { Azara, Félix de (1742- } \\
\text { 1821) }\end{array}$ & $\begin{array}{l}\text { Essais sur l'histoire natuelle des } \\
\text { quadrupèdes de la province du } \\
\text { Paraguay }\end{array}$ & París & 1801 & $\begin{array}{l}\text { Historia } \\
\text { Natural }\end{array}$ \\
\hline $\begin{array}{l}\text { Barrelier, Jacques (1606- } \\
\text { 1673) }\end{array}$ & Icones plantarum per Galliam & París & 1714 & Botánica \\
\hline $\begin{array}{l}\text { Barthez, Paul-Joseph } \\
\text { (1734-1806) }\end{array}$ & $\begin{array}{l}\text { Nouveaux éléments de la science } \\
\text { de l'homme }\end{array}$ & $\begin{array}{l}\text { Montpelli } \\
\text { er }\end{array}$ & 1778 & $\begin{array}{l}\text { Historia } \\
\text { Natural }\end{array}$ \\
\hline $\begin{array}{l}\text { Baudelocque, Jean Louis } \\
\text { (1745-1810) }\end{array}$ & L'art des accouchemens & París & 1796 & Medicina \\
\hline $\begin{array}{l}\text { Baumé, Antoine (1728- } \\
\text { 1804) }\end{array}$ & $\begin{array}{l}\text { Éléments de pharmacie théorique } \\
\text { et pratique }\end{array}$ & París & 1797 & Medicina \\
\hline \multirow{2}{*}{$\begin{array}{l}\text { Bell, Benjamín (1749- } \\
\text { 1806) }\end{array}$} & $\begin{array}{l}\text { Traité de la gonorhée virulente et } \\
\text { de la maladie vénérienne }\end{array}$ & París & 1802 & Medicina \\
\hline & $\begin{array}{l}\text { Traité théorique et pratique des } \\
\text { ulcères, }\end{array}$ & París & 1788 & Medicina \\
\hline
\end{tabular}




\begin{tabular}{|c|c|c|c|c|}
\hline $\begin{array}{l}\text { Bergius, Peter Jonas } \\
(1730-1790)\end{array}$ & Materia medica e regno vegetabili & $\begin{array}{l}\text { Estocolm } \\
\text { o }\end{array}$ & 1768 & Botánica \\
\hline \multirow{2}{*}{$\begin{array}{l}\text { Bergman, Torbern Olof } \\
\text { (1735-1784) }\end{array}$} & $\begin{array}{l}\text { Opuscules chymiques et } \\
\text { physiques }\end{array}$ & Dijon & $1780-85$ & Química \\
\hline & $\begin{array}{l}\text { Manuel du minéralogiste ou } \\
\text { sciagraphie du règne animal }\end{array}$ & París & 1772 & $\begin{array}{l}\text { Historia } \\
\text { Natural }\end{array}$ \\
\hline $\begin{array}{l}\text { Berthollet Claude Louis } \\
\text { (1748-1822) }\end{array}$ & Elémens de l'Art de la Teinture & París & 1791 & Química \\
\hline \multirow[t]{3}{*}{$\begin{array}{l}\text { Bertholon, Pierre (1741- } \\
\text { 1800) }\end{array}$} & De l'électricité des végétaux & París & 1783 & Botánica \\
\hline & Bibliothèque Britanique & Ginebra & $1786-$ & $\begin{array}{l}\text { Bibliografías } \\
\text { Catálogos } \\
\text { Enciclopedias }\end{array}$ \\
\hline & $\begin{array}{l}\text { Bibliothèque Universelle de } \\
\text { Romans }\end{array}$ & París & 1776 & Historia \\
\hline $\begin{array}{l}\text { Bichat, Xavier (1771- } \\
\text { 1802) }\end{array}$ & $\begin{array}{l}\text { Recherches physiologiques sur la } \\
\text { vie et la mort }\end{array}$ & París & 1801 & Medicina \\
\hline $\begin{array}{l}\text { Blackwell, Elizabeth } \\
(1700-1758)\end{array}$ & Herbarium Blackwellianum & $\begin{array}{l}\text { Nurembe } \\
\text { rg }\end{array}$ & 1757 & Botánica \\
\hline $\begin{array}{l}\text { Boccone, Paolo (O. Cist.) } \\
(1633-1704)\end{array}$ & $\begin{array}{l}\text { Icones \& descriptiones rariorum } \\
\text { plantarum Siciliae, Melitae, } \\
\text { Galliae, \& Italiae }\end{array}$ & Oxford & 1674 & Botánica \\
\hline $\begin{array}{l}\text { Bohác, Jan Krtitel } \\
\text { (-1768) }\end{array}$ & $\begin{array}{l}\text { De quibusdam animalibus } \\
\text { marinis }\end{array}$ & Dresden & 1761 & $\begin{array}{l}\text { Historia } \\
\text { Natural }\end{array}$ \\
\hline $\begin{array}{l}\text { Bonnet, Charles (1720- } \\
\text { 1793) }\end{array}$ & $\begin{array}{l}\text { Oeuvres d'histoire naturelle et de } \\
\text { philosophie }\end{array}$ & $\begin{array}{l}\text { Neuchate } \\
1\end{array}$ & $1779-83$ & $\begin{array}{l}\text { Historia } \\
\text { Natural }\end{array}$ \\
\hline Borbereki? & Sin identificar & -- & -- & -- \\
\hline Born, Ignaz von & $\begin{array}{l}\text { Catalogue Methodique et } \\
\text { Raisonné De La Collection Des } \\
\text { Fossiles De Mlle. Éléonore De } \\
\text { Raab }\end{array}$ & Viena & 1790 & $\begin{array}{l}\text { Historia } \\
\text { Natural }\end{array}$ \\
\hline $\begin{array}{l}\text { Borsieri de Kanilfeld, } \\
\text { Giambattista (1725-1785) }\end{array}$ & $\begin{array}{l}\text { Institutionum medicinae practicae } \\
\text { quas auditoribus suis praelegebat }\end{array}$ & Venecia & 1796 & Medicina \\
\hline $\begin{array}{l}\text { Bossut, Charles (1730- } \\
\text { 1814) }\end{array}$ & $\begin{array}{l}\text { Traité théorique et expérimental } \\
\text { d'hydrodynamique }\end{array}$ & París & 1775 & Física \\
\hline $\begin{array}{l}\text { Bouguer, Pierre (1698- } \\
\text { 1758) }\end{array}$ & $\begin{array}{l}\text { sur la Traité d'optique gradation } \\
\text { de la lumière }\end{array}$ & París & 1760 & Ciencias \\
\hline $\begin{array}{l}\text { Bouillon-Lagrange, } \\
\text { Edme-Jean-Baptiste } \\
\text { (1764-1844) }\end{array}$ & Manuel d'un cours de chimie & París & 1802 & Química \\
\hline $\begin{array}{l}\text { Boullée, Etienne Louis } \\
\text { 1728-1799 }\end{array}$ & $\begin{array}{l}\text { Mémoire sur les moyens de } \\
\text { procurer à la bibliothèque du Roi }\end{array}$ & París & 1785 & Ciencias \\
\hline
\end{tabular}




\begin{tabular}{|c|c|c|c|c|}
\hline $\begin{array}{l}\text { Bourbon-Busset, Gabriel } \\
\text { de (Leblanc) (1775-1862) }\end{array}$ & $\begin{array}{l}\text { Introduction à la science de } \\
\text { l'économie politique et de la } \\
\text { statistique générale }\end{array}$ & París & 1801 & $\begin{array}{l}\text { Economía } \\
\text { Comercio }\end{array}$ \\
\hline Bourgeois, David & Recherches sur l'art de voler & París & 1784 & Ciencias \\
\hline Boutrolle, J. B. & $\begin{array}{l}\text { Le Parfait Bouvier, ou Instruction } \\
\text { concernant la connoissance des } \\
\text { boeufs et vaches }\end{array}$ & Rouen & 1766 & Agronomía \\
\hline $\begin{array}{l}\text { Boyer, Alexis (baron) } \\
\text { (1757-1833) }\end{array}$ & Traité complet d'anatomie & París & 1797 & Medicina \\
\hline $\begin{array}{l}\text { Bridel-Brideri, Samuel } \\
\text { Elisee de (baron) (1761- } \\
\text { 1828) }\end{array}$ & $\begin{array}{l}\text { Muscologia recentiorum seu } \\
\text { analysis }\end{array}$ & París & 1797 & $\begin{array}{l}\text { Historia } \\
\text { Natural }\end{array}$ \\
\hline Bridet, Jacques Pierre & Mémoire pour le citoyen Bridet & París & $1801-02$ & Botánica \\
\hline $\begin{array}{l}\text { Brochant de Villiers, } \\
\text { André-Jean-François- } \\
\text { Marie (1772-1840) }\end{array}$ & Traité élémentaire de Minéralogie & París & $1800-01$ & $\begin{array}{l}\text { Historia } \\
\text { Natural }\end{array}$ \\
\hline $\begin{array}{l}\text { Broussonet, Pierre- } \\
\text { Marie-Auguste (1761- } \\
\text { 1807) }\end{array}$ & $\begin{array}{l}\text { Ichthyologia, sistens piscium } \\
\text { descriptiones et icones }\end{array}$ & Londres & 1782 & $\begin{array}{l}\text { Historia } \\
\text { Natural }\end{array}$ \\
\hline $\begin{array}{l}\text { Brown, John (1735- } \\
\text { 1788),Schiferli, Rudolf } \\
\text { Abraham von (1773?- } \\
\text { 1837) }\end{array}$ & $\begin{array}{l}\text { Analyse raisonnée du système de } \\
\text { John Brown }\end{array}$ & París & 1798 & Botánica \\
\hline $\begin{array}{l}\text { Bruyn, Cornelis de (1652- } \\
1726 \text { ó 1727) }\end{array}$ & Voyage au Levant & París & 1714 & $\begin{array}{l}\text { Geografía } \\
\text { Viajes }\end{array}$ \\
\hline \multirow{4}{*}{$\begin{array}{l}\text { Bulliard, Pierre (1752- } \\
\text { 1793) }\end{array}$} & Herbier de la France & París & 1780 & Botánica \\
\hline & $\begin{array}{l}\text { Dictionnaire élémentaire de } \\
\text { botanique }\end{array}$ & París & 1783 & Botánica \\
\hline & $\begin{array}{l}\text { Histoire des champignons de la } \\
\text { France }\end{array}$ & París & 1791 & Botánica \\
\hline & $\begin{array}{l}\text { Histoire des plantes vénéneuses et } \\
\text { suspectes de la France }\end{array}$ & París & 1798 & Botánica \\
\hline $\begin{array}{l}\text { Bure, Guillaume De } \\
(1734-1820)\end{array}$ & $\begin{array}{l}\text { Bibliographie instructive ou traité } \\
\text { de la connaissance des livres }\end{array}$ & París & 1763 & $\begin{array}{l}\text { Bibliografías } \\
\text { Catálogos } \\
\text { Enciclopedias }\end{array}$ \\
\hline $\begin{array}{l}\text { Burke, Edmund (1729- } \\
\text { 1797) }\end{array}$ & $\begin{array}{l}\text { Annual register, or, A view of the } \\
\text { history and politics }\end{array}$ & Londres & 1762 & $\begin{array}{l}\text { Política } \\
\text { Derecho }\end{array}$ \\
\hline \multirow{3}{*}{$\begin{array}{l}\text { Burman, Nikolaus } \\
\text { Laurens (1734-1793) }\end{array}$} & Plantarum Americanarum & $\begin{array}{l}\text { Ámsterda } \\
\text { m }\end{array}$ & 1760 & Botánica \\
\hline & $\begin{array}{l}\text { Thesaurus zeylanicus, exhibens } \\
\text { plantas in insula Zeylana } \\
\text { nascentes }\end{array}$ & $\begin{array}{l}\text { Ámsterda } \\
\text { m }\end{array}$ & 1737 & Botánica \\
\hline & Wachendorfia & $\begin{array}{l}\text { Ámsterda } \\
\mathrm{m}\end{array}$ & 1757 & Botánica \\
\hline
\end{tabular}




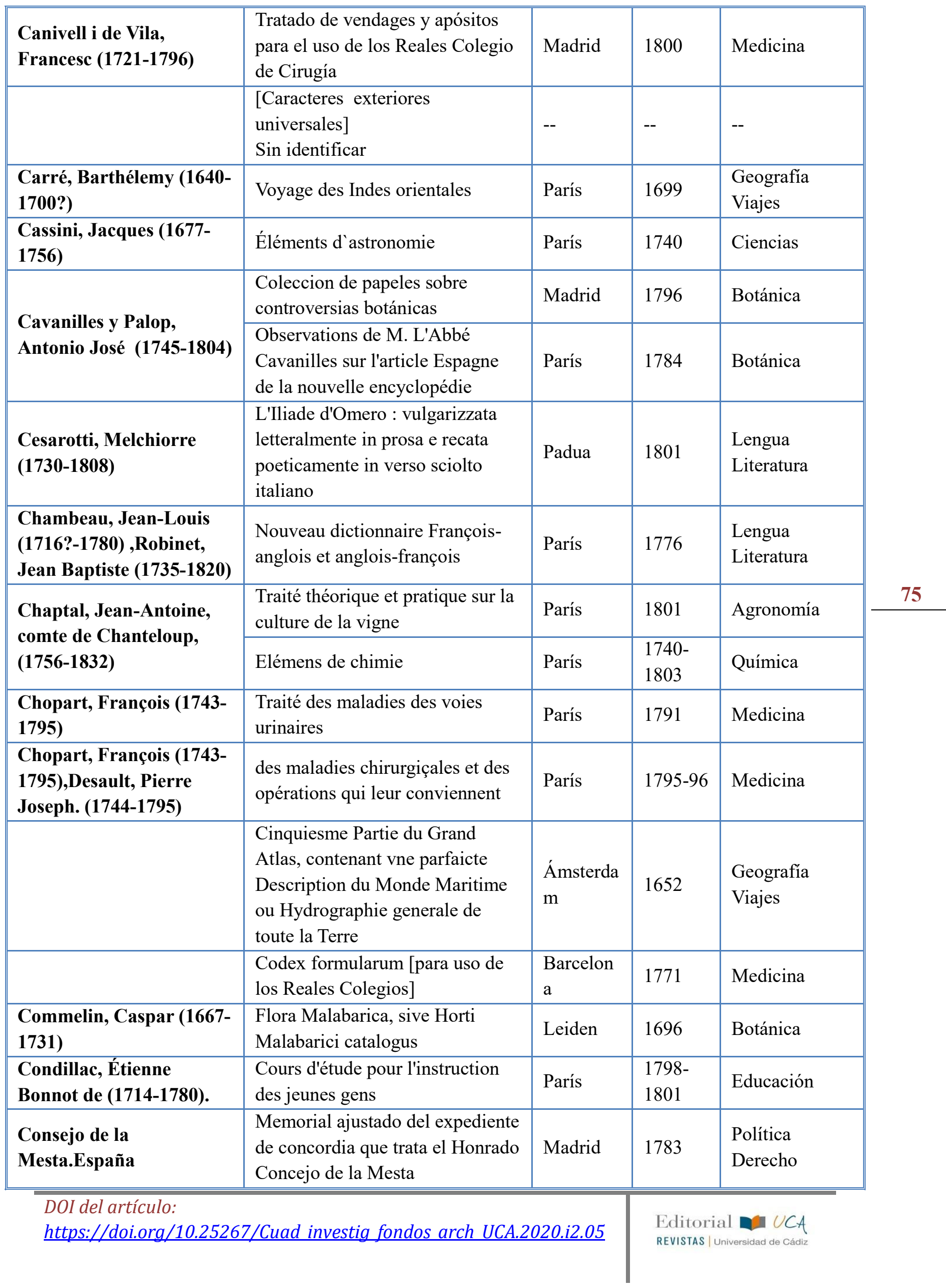




\begin{tabular}{|c|c|c|c|c|}
\hline & $\begin{array}{l}\text { Constitution de la République } \\
\text { Française } 1799\end{array}$ & París & $1798-99$ & $\begin{array}{l}\text { Política } \\
\text { Derecho }\end{array}$ \\
\hline $\begin{array}{l}\text { Cornut, Jacques Philippe } \\
(1606-1651)\end{array}$ & Canadensium plantarum & París & 1635 & Botánica \\
\hline \multirow{2}{*}{$\begin{array}{l}\text { Cullen, William (1710- } \\
\text { 1790) }\end{array}$} & Trattato di materia medica & Padua & 1792-04 & Medicina \\
\hline & Elementi di medicina pratica & Venecia & 1796 & Medicina \\
\hline \multirow{2}{*}{$\begin{array}{l}\text { Cuvier, Georges, baron } \\
(1769-1832)\end{array}$} & $\begin{array}{l}\text { Tableau élémentaire de l'histoire } \\
\text { naturelle des animaux. }\end{array}$ & París & 1798 & $\begin{array}{l}\text { Historia } \\
\text { Natural }\end{array}$ \\
\hline & Anatomie comparée de Cuvier & París & 1805 & Medicina \\
\hline $\begin{array}{l}\text { Dambourney, Louis- } \\
\text { Auguste }\end{array}$ & $\begin{array}{l}\text { Recueil de procédés et } \\
\text { d'expériences sur les teintures } \\
\text { solides que nos végétaux } \\
\text { indigènes }\end{array}$ & París & 1786 & Ciencias \\
\hline $\begin{array}{l}\text { Davila, Pedro Francisco, } \\
\text { 1713-1785 }\end{array}$ & $\begin{array}{l}\text { Catalogue systématique et } \\
\text { raisonné des curiosités de la } \\
\text { Nature et de l'Art }\end{array}$ & París & 1767 & $\begin{array}{l}\text { Historia } \\
\text { Natural }\end{array}$ \\
\hline $\begin{array}{l}\text { De Geer, Charles (1720- } \\
\text { 1778) }\end{array}$ & $\begin{array}{l}\text { Memoires pour servir a l'histoire } \\
\text { des insectes }\end{array}$ & $\begin{array}{l}\text { Estocolm } \\
\text { o }\end{array}$ & $1752-78$ & $\begin{array}{l}\text { Historia } \\
\text { Natural }\end{array}$ \\
\hline $\begin{array}{l}\text { De Grimaud, Jean } \\
\text { Charles Marguerite } \\
\text { Guillaume (1750-1789) } \\
\end{array}$ & $\begin{array}{l}\text { Cours complet, ou, Traité de } \\
\text { fiebres }\end{array}$ & $\begin{array}{l}\text { Montpelli } \\
\text { er }\end{array}$ & 1791 & Medicina \\
\hline $\begin{array}{l}\text { de Luc, Jean André } \\
\text { (1727-1817) }\end{array}$ & $\begin{array}{l}\text { Lettres physiques et morales sur } \\
\text { l'histoire de la terre et de l'homme }\end{array}$ & París & $\begin{array}{l}1779- \\
1780\end{array}$ & $\begin{array}{l}\text { Historia } \\
\text { Natural }\end{array}$ \\
\hline $\begin{array}{l}\text { Delius, Christoph } \\
\text { Traugott (1728-1779) }\end{array}$ & $\begin{array}{l}\text { Traité sur la science de } \\
\text { l'exploitation des mines par } \\
\text { theorie et pratique }\end{array}$ & París & 1778 & Ciencias \\
\hline $\begin{array}{l}\text { Demerson,Louis (17-18), } \\
\text { Larrey, Auguste (1790- } \\
\text { 1891) }\end{array}$ & $\begin{array}{l}\text { Voyage dans l'empire de Flore, ou } \\
\text { Elémens d'Histoire naturelle } \\
\text { végétale }\end{array}$ & París & 1800 & Botánica \\
\hline $\begin{array}{l}\text { Desbois de Rochefort, } \\
\text { Louis (1750-1786) }\end{array}$ & $\begin{array}{l}\text { Cours élémentaire de matière } \\
\text { médicale }\end{array}$ & París & 1789 & Medicina \\
\hline $\begin{array}{l}\text { Desfontaines, René } \\
\text { Louiche 1750-1833 }\end{array}$ & $\begin{array}{l}\text { Flora atlantica, sive Historia } \\
\text { plantarum }\end{array}$ & París & 1798 & Botánica \\
\hline $\begin{array}{l}\text { Diderot, Denis 1713-1784 } \\
\text {, Alembert, Jean Le Rond } \\
\text { d' (1717-1783) }\end{array}$ & $\begin{array}{l}\text { L'Encyclopédie méthodique ou } \\
\text { par ordre de matières par une } \\
\text { société de gens de lettres }\end{array}$ & París & $\begin{array}{l}1787- \\
1789\end{array}$ & $\begin{array}{l}\text { Bibliografías } \\
\text { Catálogos } \\
\text { Enciclopedias }\end{array}$ \\
\hline $\begin{array}{l}\text { Dillenius, Johan Jacob } \\
\text { (1684-1747) }\end{array}$ & Historia muscorum & Oxford & 1741 & $\begin{array}{l}\text { Historia } \\
\text { Natural }\end{array}$ \\
\hline $\begin{array}{l}\text { Dionisio de Halicarnaso } \\
(60-7 \mathrm{ac})\end{array}$ & $\begin{array}{l}\text { siue originum Romanorum, libri } \\
\text { decem, }\end{array}$ & Lyon & 1561 & Historia \\
\hline $\begin{array}{l}\text { Dolomieu, Déodat de } \\
\text { (1750-1801) }\end{array}$ & $\begin{array}{l}\text { Voyage aux Iles de Lipari fait en } \\
1781\end{array}$ & París & 1783 & $\begin{array}{l}\text { Geografía } \\
\text { Viajes }\end{array}$ \\
\hline Dubè, Paul (1649-1671) & $\begin{array}{l}\text { El médico y cirujano de los } \\
\text { pobres }\end{array}$ & Madrid & 1755 & Medicina \\
\hline
\end{tabular}




\begin{tabular}{|c|c|c|c|c|}
\hline \multirow{12}{*}{$\begin{array}{l}\text { Duhamel du Monceau, } \\
\text { Henri-Louis (1700-1782) }\end{array}$} & $\begin{array}{l}\text { Moyens de conserver la santé aux } \\
\text { équipages de des Vaisseaux }\end{array}$ & París & 1759 & Medicina \\
\hline & $\begin{array}{l}\text { pour les Traité de la fabrique des } \\
\text { manoeuvres vaisseaux }\end{array}$ & París & 1747 & Ciencias \\
\hline & $\begin{array}{l}\text { Mémoires sur la garance et sa } \\
\text { culture, avec la description des } \\
\text { étuves pour la dessécher, \& des } \\
\text { moulins pour la pulvériser }\end{array}$ & París & 1757 & Agronomía \\
\hline & $\begin{array}{l}\text { Traité de la conservation des } \\
\text { grains et en particulier du froment } \\
\text { (supplement) }\end{array}$ & París & 1768 & Agronomía \\
\hline & $\begin{array}{l}\text { Descriptions des arts et métiers. } \\
\text { Traité général des pêches }\end{array}$ & París & 1769 & $\begin{array}{l}\text { Historia } \\
\text { Natural }\end{array}$ \\
\hline & Éléments d'agriculture & París & 1779 & Agronomía \\
\hline & $\begin{array}{l}\text { Histoire d'un Insecte qui dévore } \\
\text { les grains de l'Angoumois }\end{array}$ & París & 1762 & $\begin{array}{l}\text { Historia } \\
\text { Natural }\end{array}$ \\
\hline & $\begin{array}{l}\text { Du transport, de la conservation } \\
\text { et de la force des Bois }\end{array}$ & París & 1767 & Agronomía \\
\hline & $\begin{array}{l}\text { Physica de los árboles, en la qual } \\
\text { se trata de la anatomía de las } \\
\text { plantas }\end{array}$ & París & 1788 & Agronomía \\
\hline & $\begin{array}{l}\text { Traité des arbres fruitiers, } \\
\text { contenant leur figure }\end{array}$ & París & 1762 & Agronomía \\
\hline & $\begin{array}{l}\text { De l'exploitation des bois, ou } \\
\text { moyen de tirer un parti } \\
\text { avantageux des taillis }\end{array}$ & París & 1764 & Agronomía \\
\hline & $\begin{array}{l}\text { Des semis et plantations des } \\
\text { arbres, et de leur culture }\end{array}$ & París & 1780 & Agronomía \\
\hline $\begin{array}{l}\text { Dumas, Charles Louis } \\
(1765-1813)\end{array}$ & Principes de Physiologie & París & 1800 & Medicina \\
\hline Ecoles normales (France) & $\begin{array}{l}\text { Séances des écoles normales, } \\
\text { recueillies par des sténographes }\end{array}$ & París & $1800-01$ & Educación \\
\hline Ellis, John (1710-1776) & $\begin{array}{l}\text { Essai sur l'histoire naturelle des } \\
\text { corallines }\end{array}$ & La Haya & 1756 & $\begin{array}{l}\text { Historia } \\
\text { Natural }\end{array}$ \\
\hline $\begin{array}{l}\text { Eloy, Nicolas François } \\
\text { Joseph (1714-1788) }\end{array}$ & $\begin{array}{l}\text { Examen de la question médico- } \\
\text { politique: si l'usage habituel de } \\
\text { caffé }\end{array}$ & Mons & 1781 & Medicina \\
\hline España [Leyes, etc] & $\begin{array}{l}\text { Novísima Recopilacion de las } \\
\text { leyes de España }\end{array}$ & $\begin{array}{l}\text { Sin } \\
\text { identifica } \\
\mathrm{r}\end{array}$ & 1805 & $\begin{array}{l}\text { Política } \\
\text { Derecho }\end{array}$ \\
\hline $\begin{array}{l}\text { Esper, Eugen Johann } \\
\text { Christoph (1742-1810) }\end{array}$ & $\begin{array}{l}\text { Icones Fucorum : cum } \\
\text { characteribus systematicis }\end{array}$ & $\begin{array}{l}\text { Nurembe } \\
\text { rg }\end{array}$ & 1799 & Botánica \\
\hline
\end{tabular}




\begin{tabular}{|c|c|c|c|c|}
\hline Esteban, Martín & $\begin{array}{l}\text { Compendio del rico aparato, y } \\
\text { hermosa architectura del Templo } \\
\text { de Salomon }\end{array}$ & Alcalá & 1615 & Historia \\
\hline $\begin{array}{l}\text { Fabricius, Johann } \\
\text { Christian (1745-1808) }\end{array}$ & Entomologia systematica & $\begin{array}{l}\text { Copenag } \\
\text { ue }\end{array}$ & $\begin{array}{l}1792- \\
98 .\end{array}$ & $\begin{array}{l}\text { Historia } \\
\text { Natural }\end{array}$ \\
\hline $\begin{array}{l}\text { Federico II, Rey de } \\
\text { Prusia (1712-1786) }\end{array}$ & $\begin{array}{l}\text { Oeuvres posthumes de Frédéric } \\
\text { II, Roi de Prusse }\end{array}$ & Berlín & $1788-89$ & Historia \\
\hline $\begin{array}{l}\text { Ferguson, Adam (1723- } \\
\text { 1816) }\end{array}$ & $\begin{array}{l}\text { Histoire des progrès et de la chûte } \\
\text { de la République romaine }\end{array}$ & París & $1784-91$ & Historia \\
\hline $\begin{array}{l}\text { Fermin, Philippe (1720- } \\
\text { 1790) }\end{array}$ & $\begin{array}{l}\text { Histoire naturelle de la Hollande } \\
\text { équinoxiale }\end{array}$ & $\begin{array}{l}\text { Ámsterda } \\
\mathrm{m}\end{array}$ & 1765 & $\begin{array}{l}\text { Historia } \\
\text { Natural }\end{array}$ \\
\hline $\begin{array}{l}\text { Ferrière, Claude de } \\
\text { (1639-1715), Massé, A. J. } \\
(1771-)\end{array}$ & $\begin{array}{l}\text { La science parfaite des notaires } \\
\text { ou le parfait notaire }\end{array}$ & Mouchet & 1758 & $\begin{array}{l}\text { Política } \\
\text { Derecho }\end{array}$ \\
\hline $\begin{array}{l}\text { Feuillée, Louis (1660- } \\
\text { 1732) }\end{array}$ & $\begin{array}{l}\text { Journal des observations } \\
\text { physiques, mathematiques et } \\
\text { botaniques }\end{array}$ & París & 1714 & Ciencias \\
\hline \multirow{2}{*}{$\begin{array}{l}\text { Forskal, Pierre (1732- } \\
\text { 1763) }\end{array}$} & Icones rerum naturalium & $\begin{array}{l}\text { Copenag } \\
\text { ue }\end{array}$ & 1776 & Botánica \\
\hline & Flora aegyptiaco-arabica & $\begin{array}{l}\text { Copenag } \\
\text { ue }\end{array}$ & 1775 & Botánica \\
\hline $\begin{array}{l}\text { Forskal, Pierre (1732- } \\
\text { 1763), Vahl, Martin } \\
\text { Hendriksen, (1749-1804) }\end{array}$ & $\begin{array}{l}\text { Symbolae botanicae, sive } \\
\text { Plantarum }\end{array}$ & $\begin{array}{l}\text { Copenag } \\
\text { ue }\end{array}$ & $1790-94$ & Botánica \\
\hline \multirow{4}{*}{$\begin{array}{l}\text { Fourcroy, Antoine- } \\
\text { François de, comte (1755- } \\
\text { 1809) }\end{array}$} & Tableaux synoptiques de chimie & París & 1799 & Química \\
\hline & $\begin{array}{l}\text { Système des Connaissances } \\
\text { chimiques }\end{array}$ & París & $1800-02$ & Química \\
\hline & $\begin{array}{l}\text { La Médecine éclairée par les } \\
\text { sciences physiques }\end{array}$ & París & 1791 & Medicina \\
\hline & $\begin{array}{l}\text { Philosophie chimique, ou Vérités } \\
\text { fondamentales de la chimie } \\
\text { moderne, }\end{array}$ & París & $1794-95$ & Química \\
\hline $\begin{array}{l}\text { Franck von Franckenau, } \\
\text { Georg (1643-1704) }\end{array}$ & $\begin{array}{l}\text { De palingenesia sive } \\
\text { resuscitatione artificiali } \\
\text { plantarum }\end{array}$ & Halle & 1717 & $\begin{array}{l}\text { Historia } \\
\text { Natural }\end{array}$ \\
\hline $\begin{array}{l}\text { Frank, Joseph (1771- } \\
\text { 1842) }\end{array}$ & Ratio instituti clinici Ticinensis & Viena & 1797 & Medicina \\
\hline $\begin{array}{l}\text { Fredrik Hasselquist, } \\
\text { Fredrik }\end{array}$ & Voyages dans le Levant, & París & 1769 & $\begin{array}{l}\text { Historia } \\
\text { Natural }\end{array}$ \\
\hline $\begin{array}{l}\text { Gaertner, Joseph (1732- } \\
\text { 1791) }\end{array}$ & $\begin{array}{l}\text { De fructibus et seminibus } \\
\text { plantarum }\end{array}$ & Stuttgard & 1788 & Botánica \\
\hline $\begin{array}{l}\text { Garonne, Paulet Leon } \\
(17 . . .-18---)\end{array}$ & $\begin{array}{l}\text { Mémoire historique et politique } \\
\text { sur le commerce de l'Inde }\end{array}$ & París & 1802 & $\begin{array}{l}\text { Política } \\
\text { Derecho }\end{array}$ \\
\hline
\end{tabular}




\begin{tabular}{|c|c|c|c|c|}
\hline Garriga, José, (1765-?) & $\begin{array}{l}\text { Continuación y suplemento del } \\
\text { Prontuario de Don Severo } \\
\text { Aguirre }\end{array}$ & Madrid & 1802 & $\begin{array}{l}\text { Política } \\
\text { Derecho }\end{array}$ \\
\hline $\begin{array}{l}\text { Gibelin, Jacques (trad.) } \\
\text { (1744-1828) }\end{array}$ & $\begin{array}{l}\text { Expériences et observations sur } \\
\text { différentes branches de la } \\
\text { physique }\end{array}$ & París & 1782 & Física \\
\hline $\begin{array}{l}\text { Girod-Chantrans, Justin } \\
(1750-1841)\end{array}$ & $\begin{array}{l}\text { Recherches chimiques et } \\
\text { microscopiques sur les conferves, } \\
\text { bisses, tremelles }\end{array}$ & París & 1802 & Química \\
\hline $\begin{array}{l}\text { Glachant, François } \\
\text { Michael (-1783), Alais de } \\
\text { Beauville. }\end{array}$ & Nouveau traité d'écriture & París & 1742 & $\begin{array}{l}\text { Lengua } \\
\text { Literatura }\end{array}$ \\
\hline $\begin{array}{l}\text { Gmelin, Johann Georg } \\
\text { (1709-1755) }\end{array}$ & $\begin{array}{l}\text { Flora Sibirica sive historia } \\
\text { plantarum Sibiriae }\end{array}$ & $\begin{array}{l}\text { San } \\
\text { Petersbur } \\
\text { go }\end{array}$ & 1747 & Botánica \\
\hline $\begin{array}{l}\text { Gmelin, Samuel Gottlieb } \\
\text { (1744-1774) }\end{array}$ & $\begin{array}{l}\text { Histoire des découvertes faites } \\
\text { par divers savans voyageurs }\end{array}$ & Berna & $1779-87$ & $\begin{array}{l}\text { Geografía } \\
\text { Viajes }\end{array}$ \\
\hline \multirow{2}{*}{$\begin{array}{l}\text { Gottsched, Johann } \\
\text { Christoph (1700-1766) }\end{array}$} & Kern der Deutschen Sprachkunst & Leipzig & 1753 & $\begin{array}{l}\text { Lengua } \\
\text { Literatura }\end{array}$ \\
\hline & Le Maître de la langue allemande & $\begin{array}{l}\text { Estrasbur } \\
\text { go }\end{array}$ & 1787 & $\begin{array}{l}\text { Lengua } \\
\text { Literatura }\end{array}$ \\
\hline Goudar, Ludovico & $\begin{array}{l}\text { Nuova gramatica italiana y } \\
\text { francesa }\end{array}$ & Pinerolo & 1785 & $\begin{array}{l}\text { Lengua } \\
\text { Literatura }\end{array}$ \\
\hline \multirow[t]{2}{*}{ Goulin, Jean (1728-1799) } & Le médecin des dames & París & 1773 & Medicina \\
\hline & $\begin{array}{l}\text { Guía de forasteros para el año } \\
1811 \text { de la isla de Cuba }\end{array}$ & Cuba & [1811] & $\begin{array}{l}\text { Bibliografías } \\
\text { Catálogos } \\
\text { Enciclopedias }\end{array}$ \\
\hline Guidi, Louis (1710-1780) & Ame des bêtes & París & 1782 & $\begin{array}{l}\text { Historia } \\
\text { Natural }\end{array}$ \\
\hline $\begin{array}{l}\text { Gumilla, José (1686- } \\
\text { 1750) }\end{array}$ & $\begin{array}{l}\text { Histoire naturelle, civile et } \\
\text { géographique de l'Orénoque }\end{array}$ & Avignon & 1758 & $\begin{array}{l}\text { Historia } \\
\text { Natural }\end{array}$ \\
\hline $\begin{array}{l}\text { Guyton de Morveau, } \\
\text { Louis-Bernard (baron) } \\
\text { (1737-1816) }\end{array}$ & $\begin{array}{l}\text { Méthode de Nomenclature } \\
\text { chimique }\end{array}$ & París & 1787 & Química \\
\hline $\begin{array}{l}\text { Guyton de Morveau, N. } \\
(1770-1785), \text { Lavoisier, } \\
\text { Antoine-Laurent de } \\
(1743-1794)\end{array}$ & Annales de Chimie & París & 1789 & Química \\
\hline Habesci, Elias & État actuel de l'Empire ottoman & París & 1792 & Historia \\
\hline \multirow{2}{*}{$\begin{array}{l}\text { Haller, Albrecht von } \\
\text { (1708-1777) }\end{array}$} & $\begin{array}{l}\text { Historia stirpium indigenarum } \\
\text { Helvetiæ inchoata }\end{array}$ & Berna & 1768 & Botánica \\
\hline & $\begin{array}{l}\text { Enumeratio methodica stirpium } \\
\text { Helvetiae }\end{array}$ & Gottinga & 1742 & Botánica \\
\hline
\end{tabular}




\begin{tabular}{|c|c|c|c|c|}
\hline $\begin{array}{l}\text { Haüy, René Just (1743- } \\
\text { 1822) }\end{array}$ & Traite de mineralogie & París & 1801 & $\begin{array}{l}\text { Historia } \\
\text { Natural }\end{array}$ \\
\hline Hayne, Friedrich Gottlob & $\begin{array}{l}\text { Termini botanici iconibus } \\
\text { illustrati }\end{array}$ & Berlín & 1799 & Botánica \\
\hline \multirow[b]{2}{*}{$\begin{array}{l}\text { Hedwig, Johannes (1730- } \\
\text { 1799) }\end{array}$} & Species muscorum frondosorum & Leipzig & 1801 & $\begin{array}{l}\text { Historia } \\
\text { Natural }\end{array}$ \\
\hline & $\begin{array}{l}\text { Theoria generationis et } \\
\text { fructificationis plantarum } \\
\text { cryptogamicarum Linnaei }\end{array}$ & $\begin{array}{l}\text { San } \\
\text { Petersbur } \\
\text { go }\end{array}$ & 1784 & Botánica \\
\hline \multirow{3}{*}{$\begin{array}{l}\text { Hoffmann,Georg, Franz } \\
\text { (1761-1826) }\end{array}$} & $\begin{array}{l}\text { De Vario lichenum usu } \\
\text { commentatio, sectio }\end{array}$ & Erlangen & 1786 & Botánica \\
\hline & Observationes botanicae & Erlangen & 1789 & Botánica \\
\hline & $\begin{array}{l}\text { Vegetabilia in Hercyniae } \\
\text { subterraneis collecta }\end{array}$ & $\begin{array}{l}\text { Nurembe } \\
\text { rg }\end{array}$ & 1787 & Botánica \\
\hline $\begin{array}{l}\text { Horacio Flaco, Quinto } \\
\text { (65-8 ac), Jouvency, } \\
\text { Joseph }\end{array}$ & $\begin{array}{l}\text { expurgata et accuratis notis } \\
\text { illustrata }\end{array}$ & Sevilla & 1729 & Historia \\
\hline $\begin{array}{l}\text { Hourcastremé, Pierre } \\
(1742-1815)\end{array}$ & $\begin{array}{l}\text { Les aventures de Messire } \\
\text { Anselme, chevalier des lois }\end{array}$ & París & 1792 & Historia \\
\hline $\begin{array}{l}\text { Humboldt, Alexander } \\
\text { von (1769-1859) }\end{array}$ & $\begin{array}{l}\text { Florae fribergensis specimen, } \\
\text { plantas cryptogamicas }\end{array}$ & Berlín & 1793 & Botánica \\
\hline Hunter, John (1728-1793) & Traité des maladies vénériennes & París & 1787 & Medicina \\
\hline $\begin{array}{l}\text { Husson, Henri-Marie } \\
(1772-1853)\end{array}$ & $\begin{array}{l}\text { Recherches historiques et } \\
\text { médicales sur la vaccine }\end{array}$ & París & 1801 & Medicina \\
\hline $\begin{array}{l}\text { Imprimerie Chrétienne } \\
\text { (París, Francia) }\end{array}$ & $\begin{array}{l}\text { Conférences publiques sur le } \\
\text { schisme de France, décrétées par } \\
\text { le second Concile national }\end{array}$ & París & 1801 & Religión \\
\hline \multirow[t]{2}{*}{$\begin{array}{l}\text { Institut National des } \\
\text { Sciences et Arts (Paris) }\end{array}$} & $\begin{array}{l}\text { Mémoires de l'Institut national } \\
\text { des Sciences et Arts pour l'an IV }\end{array}$ & París & $1798-$ & Ciencias \\
\hline & $\begin{array}{l}\text { Institutionum medicinalium.[sin } \\
\text { identificar. Se podría referir a } \\
\text { algúno de los tomos de la obra de } \\
\text { Borsieri de Kanilfeld, } \\
\text { Giambattista, Institutionum } \\
\text { medicinae practicae] }\end{array}$ & -- & -- & Medicina \\
\hline \multirow{2}{*}{$\begin{array}{l}\text { Jacquin, Nikolaus } \\
\text { Joseph, Freiherr von } \\
(1727-1817)\end{array}$} & $\begin{array}{l}\text { selectarum stirpium } \\
\text { Americanorum Historia }\end{array}$ & Viena & 1793 & Botánica \\
\hline & $\begin{array}{l}\text { Collectanea ad botanicam, } \\
\text { chemiam, et historiam naturalem } \\
\text { spectantia }\end{array}$ & Viena & 1786 & Botánica \\
\hline $\begin{array}{l}\text { Johnson, Samuel (1709- } \\
\text { 1784) }\end{array}$ & Le paresseux & París & 1790 & Historia \\
\hline
\end{tabular}




\begin{tabular}{|c|c|c|c|c|}
\hline $\begin{array}{l}\text { Jones, Robert (1781- } \\
\text { 1818) }\end{array}$ & $\begin{array}{l}\text { Ricerche sullo stato della } \\
\text { medicina secondo i principii della } \\
\text { filosofia induttiva }\end{array}$ & Venecia & 1803 & Medicina \\
\hline & Journal d'un voyage de Genève & Ginebra & 1792 & $\begin{array}{l}\text { Geografía } \\
\text { Viajes }\end{array}$ \\
\hline $\begin{array}{l}\text { Kaempfer, Engelbert } \\
\text { (1651-1716) }\end{array}$ & $\begin{array}{l}\text { Amoenitatum exoticarum } \\
\text { politico-physico-medicarum }\end{array}$ & Lemgo & 1712 & Botánica \\
\hline $\begin{array}{l}\text { Koch, Christophe de } \\
\text { (1737-1813) }\end{array}$ & $\begin{array}{l}\text { Abrégé de l'Histoire des traités de } \\
\text { paix entre les puissances de } \\
\text { l'Europe }\end{array}$ & Basilea & 1797 & Historia \\
\hline $\begin{array}{l}\text { La Billardiere, Jacques- } \\
\text { Julien Houtou de (1755- } \\
\text { 1834) }\end{array}$ & Icones plantarum Syriae rariorum & París & 1795 & Botánica \\
\hline \multirow[t]{3}{*}{$\begin{array}{l}\text { La Condamine Charles } \\
\text { Marie de, }(1701-1774)\end{array}$} & $\begin{array}{l}\text { Journal du voyage fait par ordre } \\
\text { du Roi }\end{array}$ & París & 1754 & $\begin{array}{l}\text { Geografía } \\
\text { Viajes }\end{array}$ \\
\hline & La Connaissance des temps & París & 1798-99 & Historia \\
\hline & La France littéraire & París & 1769 & $\begin{array}{l}\text { Bibliografías } \\
\text { Catálogos } \\
\text { Enciclopedias }\end{array}$ \\
\hline $\begin{array}{l}\text { La Garaye, Claude } \\
\text { Toussaint Marot comte } \\
\text { de (1675-1755) }\end{array}$ & $\begin{array}{l}\text { Chymie hydraulique pour extraire } \\
\text { les sels essentiels des végétaux }\end{array}$ & París & 1775 & Botánica \\
\hline $\begin{array}{l}\text { Laet, Johannes de (1593- } \\
\text { 1649) }\end{array}$ & $\begin{array}{l}\text { De Imperio Magni Mogolis, sive } \\
\text { India vera commentarius }\end{array}$ & Lyon & 1631 & Historia \\
\hline $\begin{array}{l}\text { Lafitau, Joseph-François } \\
\text { (1681-1746) }\end{array}$ & $\begin{array}{l}\text { Mœurs des sauvages amériquains, } \\
\text { comparées aux mœurs }\end{array}$ & París & 1724 & Historia \\
\hline \multirow{2}{*}{$\begin{array}{l}\text { Lavoisier, Antoine- } \\
\text { Laurent de (1743-1794) }\end{array}$} & Traité élémentaire de Chimie & París & 1793 & Química \\
\hline & $\begin{array}{l}\text { Opuscules physiques et } \\
\text { chimiques }\end{array}$ & París & 1801 & Química \\
\hline $\begin{array}{l}\text { Le Comte, Louis (1655- } \\
\text { 1728) }\end{array}$ & $\begin{array}{l}\text { Nouveaux mémoires sur l'état } \\
\text { présent de la Chine }\end{array}$ & París & 1698 & $\begin{array}{l}\text { Geografía } \\
\text { Viajes }\end{array}$ \\
\hline Le Pileur d'Appligny, M. & $\begin{array}{l}\text { Instructions sur l'art de faire la } \\
\text { bière }\end{array}$ & París & 1783 & Agronomía \\
\hline $\begin{array}{l}\text { Le Trosne, Guillaume- } \\
\text { François (1728-1780) }\end{array}$ & $\begin{array}{l}\text { Recueil de plusieurs morceaux } \\
\text { economiques }\end{array}$ & $\begin{array}{l}\text { Ámsterda } \\
\text { m }\end{array}$ & 1768 & $\begin{array}{l}\text { Economía } \\
\text { Comercio }\end{array}$ \\
\hline $\begin{array}{l}\text { Lenoir, Alexandre } \\
\text { [Marie-Alexandre] (1762- } \\
\text { 1832) }\end{array}$ & $\begin{array}{l}\text { Description historique et } \\
\text { chronologique des monumens de } \\
\text { sculpture réunis au Musée des } \\
\text { monumens français }\end{array}$ & París & 1800 & Historia \\
\hline $\begin{array}{l}\text { Leroy, Alphonse Louis } \\
\text { Vincent (1742-1816) }\end{array}$ & Pratique des accouchements & París & 1776 & Medicina \\
\hline $\begin{array}{l}\text { Licurgo (390-324?a.c), } \\
\text { Auger, Athanase (1734- } \\
\text { 1792) }\end{array}$ & $\begin{array}{l}\text { Discours de Lycurgue, } \\
\text { d'Andocide, d'Isée, de Dinarque, } \\
\text { avec un fragment sous le nom de }\end{array}$ & París & 1783 & Historia \\
\hline
\end{tabular}




\begin{tabular}{|c|c|c|c|c|}
\hline & $\begin{array}{l}\text { Démade ...Lycurgue; Athanase } \\
\text { Auger }\end{array}$ & & & \\
\hline Liger, Louis (1658-1717) & $\begin{array}{l}\text { La nouvelle maison rustique : ou } \\
\text { Economie rurale, pratique et } \\
\text { générale de tous les biens de } \\
\text { campagne }\end{array}$ & París & 1790 & Agronomía \\
\hline \multirow{12}{*}{$\begin{array}{l}\text { Linné, Carl von (1707- } \\
\text { 1778) }\end{array}$} & Bibliotheca botanica & $\begin{array}{l}\text { Ámsterda } \\
m\end{array}$ & 1736 & Botánica \\
\hline & Sistema plantarum Europae & Cologny & $\begin{array}{l}\text { 1785- } \\
1787 .-\end{array}$ & Botánica \\
\hline & $\begin{array}{l}\text { Genera plantarum eorumque } \\
\text { characteres naturales }\end{array}$ & Fráncfort & 1778 & Botánica \\
\hline & $\begin{array}{l}\text { Systema Vegetabilium, secundum } \\
\text { classes, ordines, genera, }\end{array}$ & Gottinga & 1774 & Botánica \\
\hline & $\begin{array}{l}\text { Classes Plantarum, seu systemata } \\
\text { plantarum }\end{array}$ & Halle & 1747 & Botánica \\
\hline & $\begin{array}{l}\text { Pralectiones in ordines naturales } \\
\text { plantarum e proprio }\end{array}$ & $\begin{array}{l}\text { Hamburg } \\
\text { o }\end{array}$ & 1792 & Botánica \\
\hline & $\begin{array}{l}\text { Museum ... Adolphi Friderici, } \\
\text { Regis Suecorum, ... in quo } \\
\text { animalia rariora .. }\end{array}$ & $\begin{array}{l}\text { Estocolm } \\
\text { o }\end{array}$ & 1754 & $\begin{array}{l}\text { Historia } \\
\text { Natural }\end{array}$ \\
\hline & $\begin{array}{l}\text { Flora zeylanica : sistens plantas } \\
\text { indicas Zeylonae insulae }\end{array}$ & $\begin{array}{l}\text { Estocolm } \\
\text { o }\end{array}$ & 1747 & Botánica \\
\hline & $\begin{array}{l}\text { Amoenitates academicae seu } \\
\text { Dissertationes variae physicae }\end{array}$ & Leiden & $1749-64$ & Botánica \\
\hline & Systema naturae, & París & 1744 & Botánica \\
\hline & $\begin{array}{l}\text { philosophia botanica, in qua } \\
\text { explicantur fundamenta botanica }\end{array}$ & Viena & 1770 & Botánica \\
\hline & suplementum plantarum & & 1781 & Botánica \\
\hline $\begin{array}{l}\text { Lisias (440?-380 a.c.) ; } \\
\text { Auger, Athanase (1734- } \\
\text { 1792) }\end{array}$ & Euvres completes de Lysias & París & 1783 & $\begin{array}{l}\text { Bibliografías } \\
\text { Catálogos } \\
\text { Enciclopedias }\end{array}$ \\
\hline $\begin{array}{l}\text { Literary and } \\
\text { Philosophical Society } \\
\text { (Manchester) }\end{array}$ & $\begin{array}{l}\text { [Memoirs of the Literary and } \\
\text { Philosophical Society of } \\
\text { Manchester] }\end{array}$ & Londres & 1789 & $\begin{array}{l}\text { Lengua } \\
\text { Literatura }\end{array}$ \\
\hline $\begin{array}{l}\text { Loisel, Pierre (1750- } \\
\text { 1812?) }\end{array}$ & Essai sur lart de la verrerie & París & $\begin{array}{l}1799- \\
1800\end{array}$ & Agronomía \\
\hline $\begin{array}{l}\text { Loureiro, Joao de (1715- } \\
\text { 1796) }\end{array}$ & $\begin{array}{l}\text { Flora Cochinchinensis, sistens } \\
\text { plantas in regno Cochinchina }\end{array}$ & París & 1793 & Botánica \\
\hline $\begin{array}{l}\text { Luis XVI, Rey de Francia } \\
(1754-1793)\end{array}$ & $\begin{array}{l}\text { Ouvertures des Etats-Généraux, } \\
\text { faite à Versailles }\end{array}$ & París & 1789 & $\begin{array}{l}\text { Política } \\
\text { Derecho }\end{array}$ \\
\hline $\begin{array}{l}\text { Macquer, Pierre Joseph } \\
\text { (1718-1784) }\end{array}$ & Art de la teinture en soie & París & 1763 & Química \\
\hline
\end{tabular}




\begin{tabular}{|c|c|c|c|c|}
\hline $\begin{array}{l}\text { Madrisio, Niccolò (1656- } \\
\text { 1729) }\end{array}$ & $\begin{array}{l}\text { Viaggi per l'Italia, Francia, e } \\
\text { Germania }\end{array}$ & Venecia & 1718 & $\begin{array}{l}\text { Geografía } \\
\text { Viajes }\end{array}$ \\
\hline $\begin{array}{l}\text { Manuel, Louis-Pierre } \\
\text { (1751-1793) }\end{array}$ & $\begin{array}{l}\text { Essais historiques, critiques, } \\
\text { littéraires et philosophiques }\end{array}$ & Ginebra & 1783 & Historia \\
\hline $\begin{array}{l}\text { Marschall von } \\
\text { Bieberstein, Friedrich } \\
\text { August Freiherr (1768- } \\
\text { 1826) }\end{array}$ & $\begin{array}{l}\text { Tableau des provinces situées sur } \\
\text { la côte occidentale de la mer } \\
\text { Caspienne }\end{array}$ & $\begin{array}{l}\text { San } \\
\text { Petersbur } \\
\text { go }\end{array}$ & 1798 & $\begin{array}{l}\text { Geografía } \\
\text { Viajes }\end{array}$ \\
\hline $\begin{array}{l}\text { Mattioli, Pietro Andrea } \\
(1500-1577)\end{array}$ & $\begin{array}{l}\text { Commentaires sur les six livres } \\
\text { de la matière médecinale de } \\
\text { Pedacius Dioscoride }\end{array}$ & Lyon & 1680 & Medicina \\
\hline $\begin{array}{l}\text { Mauricio, Conde de Saxe } \\
(1696-1750)\end{array}$ & $\begin{array}{l}\text { Historia de Mauricio, Conde de } \\
\text { Saxe }\end{array}$ & $\begin{array}{l}\text { San } \\
\text { Sebastián }\end{array}$ & 1745 & Historia \\
\hline $\begin{array}{l}\text { Michaux, André (1746- } \\
\text { 1802) }\end{array}$ & $\begin{array}{l}\text { Histoire des chènes de } \\
\text { l'Amérique septentrionale }\end{array}$ & París & 1801 & Botánica \\
\hline $\begin{array}{l}\text { Model, Johan-Georg } \\
(1711-1775)\end{array}$ & $\begin{array}{l}\text { Récréations physiques, } \\
\text { économiques et chimiques }\end{array}$ & París & 1774 & Física \\
\hline $\begin{array}{l}\text { Monro, Alexandre (1727- } \\
\text { 1802) }\end{array}$ & $\begin{array}{l}\text { Médecine de l'armée, ou Traité } \\
\text { des maladies communes des } \\
\text { troupes }\end{array}$ & París & 1769 & Medicina \\
\hline $\begin{array}{l}\text { Monte, Giovanni Battista } \\
\text { da }(1498-1551)\end{array}$ & $\begin{array}{l}\text { Consultationum medicinalium } \\
\text { centuria secunda }\end{array}$ & Venecia & 1556 & Medicina \\
\hline $\begin{array}{l}\text { Mutis y Bosio, José } \\
\text { Celestino (1732-1808) }\end{array}$ & $\begin{array}{l}\text { Iosephi Caelestini Mutis caryocar } \\
\text { Amygdaliferum cusante Ant. } \\
\text { Iosepho Cavanilles }\end{array}$ & [Madrid] & $\begin{array}{l}{[1797-} \\
98]\end{array}$ & Botánica \\
\hline Nicquet, H., ? & Phisiognomia & & 1651 & $\begin{array}{l}\text { Historia } \\
\text { Natural }\end{array}$ \\
\hline $\begin{array}{l}\text { Niebuhr, Carsten (1733- } \\
\text { 1815) }\end{array}$ & $\begin{array}{l}\text { Description de l'Arabie d'après } \\
\text { les observations et recherches } \\
\text { faites dans le pays }\end{array}$ & Gottinga & 1773 & $\begin{array}{l}\text { Geografía } \\
\text { Viajes }\end{array}$ \\
\hline $\begin{array}{l}\text { Nöel, François-Joseph- } \\
\text { Michel (1756-1841) }\end{array}$ & $\begin{array}{l}\text { Dictionnaire de la Table, ou } \\
\text { Mythologie grecque, latine, } \\
\text { egyptienne, celtique }\end{array}$ & París & 1801 & Historia \\
\hline $\begin{array}{l}\text { O'Heguerty, Pierre- } \\
\text { André (1700-1763) }\end{array}$ & $\begin{array}{l}\text { Essai sur les interests du } \\
\text { commerce maritime }\end{array}$ & La Haya & 1777 & $\begin{array}{l}\text { Economía } \\
\text { Comercio }\end{array}$ \\
\hline $\begin{array}{l}\text { Olivier, Guillaume- } \\
\text { Antoine (1756-1814) }\end{array}$ & $\begin{array}{l}\text { Entomologie,ou Histoire naturelle } \\
\text { des insectes }\end{array}$ & París & 1789 & $\begin{array}{l}\text { Historia } \\
\text { Natural }\end{array}$ \\
\hline \multirow{2}{*}{$\begin{array}{l}\text { Pallas, Peter Simon } \\
\text { (1741-1811) }\end{array}$} & $\begin{array}{l}\text { Miscellanea zoologica, quibus } \\
\text { nov imprimis atque obscur } \\
\text { animalium species describuntur }\end{array}$ & La Haya & 1760 & $\begin{array}{l}\text { Historia } \\
\text { Natural }\end{array}$ \\
\hline & $\begin{array}{l}\text { Elenchus zoophytorum sistens } \\
\text { generum adumbrationes } \\
\text { generaliore }\end{array}$ & La Haya & 1766 & Botánica \\
\hline
\end{tabular}




\begin{tabular}{|c|c|c|c|c|}
\hline & $\begin{array}{l}\text { Voyage de M.P.S. Pallas, en } \\
\text { différentes provinces de l'Empire } \\
\text { de Rusie et dans l'Asie } \\
\text { Septentrionale }\end{array}$ & París & $\begin{array}{l}1788- \\
93 .\end{array}$ & Botánica \\
\hline & $\begin{array}{l}\text { Flora Rossica seu stirpium } \\
\text { Imperii Rossici per Europam et } \\
\text { Asiam }\end{array}$ & $\begin{array}{l}\text { San } \\
\text { Petersbur } \\
\text { go }\end{array}$ & $1784-88$ & Botánica \\
\hline \multirow{6}{*}{$\begin{array}{l}\text { Parmentier, Antoine } \\
\text { Augustin (1737-1813) }\end{array}$} & $\begin{array}{l}\text { Avis aux bonnes ménagères des } \\
\text { villes et des campagnes, sur la } \\
\text { meilleure manière de faire leur } \\
\text { pain }\end{array}$ & Londres & 1792 & Agronomía \\
\hline & Traité de la Châtaigne & París & 1780 & Agronomía \\
\hline & $\begin{array}{l}\text { Expériences et réflexions } \\
\text { relatives à l'analyse du blé et des } \\
\text { farines }\end{array}$ & París & 1781 & Agronomía \\
\hline & $\begin{array}{l}\text { Recherches sur les végétaux } \\
\text { nourrissans }\end{array}$ & París & 1781 & Botánica \\
\hline & $\begin{array}{l}\text { Mémoires sur les avantages que } \\
\text { la province du Languedoc }\end{array}$ & París & 1786 & Agronomía \\
\hline & $\begin{array}{l}\text { Traité sur la culture et les usages } \\
\text { de la patate, de la pomme de terre }\end{array}$ & París & 1789 & Agronomía \\
\hline \multirow{3}{*}{$\begin{array}{l}\text { Persoon, Christiaan } \\
\text { Henrik (1755-1837) }\end{array}$} & $\begin{array}{l}\text { Icones et descriptiones fungorum } \\
\text { minus cognitorum }\end{array}$ & Leipzig & 1798 & Botánica \\
\hline & Synopsis methodica fungorum & Gottinga & 1801 & Botánica \\
\hline & $\begin{array}{l}\text { Tentamen dispositionis } \\
\text { methodicae fungorum in classes }\end{array}$ & Leipzig & 1797 & Botánica \\
\hline Picco, Vittorio & Melethemata inauguralia & & 1788 & Botánica \\
\hline \multirow{2}{*}{ Piso, Willem (1611-1678) } & $\begin{array}{l}\text { De Indi utriusque re naturali et } \\
\text { medica libri quatuordecim }\end{array}$ & $\begin{array}{l}\text { Ámsterda } \\
\mathrm{m}\end{array}$ & 1658 & $\begin{array}{l}\text { Historia } \\
\text { Natural }\end{array}$ \\
\hline & Historia Naturalis Brasiliae & $\begin{array}{l}\text { Ámsterda } \\
\mathrm{m}\end{array}$ & 1648 & $\begin{array}{l}\text { Historia } \\
\text { Natural }\end{array}$ \\
\hline \multirow{3}{*}{$\begin{array}{l}\text { Plumier, Charles (1646- } \\
\text { 1704) }\end{array}$} & $\begin{array}{l}\text { Description des Plantes de } \\
\text { l'Amérique }\end{array}$ & París & 1643 & Botánica \\
\hline & Filicetum americanarum & París & 1703 & Botánica \\
\hline & Traité des fougères de l'Amérique & París & 1705 & Botánica \\
\hline $\begin{array}{l}\text { Poli, Giuseppe Saverio } \\
(1746-1825)\end{array}$ & $\begin{array}{l}\text { Elementi di fisica sperimentale } \\
\text { composti per uso della regia } \\
\text { universita }\end{array}$ & Venecia & 1796 & Física \\
\hline $\begin{array}{l}\text { Pontedera, Giulio (1688- } \\
\text { 1757) }\end{array}$ & $\begin{array}{l}\text { Compendium tabularum } \\
\text { botanicarum,.. }\end{array}$ & Padua & 1718 & Botánica \\
\hline $\begin{array}{l}\text { Portalis, Jean-Etienne- } \\
\text { Marie (1745-1807) }\end{array}$ & $\begin{array}{l}\text { Organisation des } \\
\text { cultes.Convention Nationale de } \\
\text { France }\end{array}$ & París & 1790 & $\begin{array}{l}\text { Política } \\
\text { Derecho }\end{array}$ \\
\hline
\end{tabular}




\begin{tabular}{|c|c|c|c|c|}
\hline $\begin{array}{l}\text { Priestley, Joseph (1733- } \\
\text { 1804) }\end{array}$ & Histoire de l'électricité, & París & 1771 & Ciencias \\
\hline & $\begin{array}{l}\text { Procès-verbal des séances de } \\
\text { l'administration du département } \\
\text { de la Meurthe }\end{array}$ & Nancy & 1791 & $\begin{array}{l}\text { Política } \\
\text { Derecho }\end{array}$ \\
\hline $\begin{array}{l}\text { Puisieux, Madeleine de } \\
(1720-1798)\end{array}$ & Mémoires d'un homme de bien & París & 1768 & Educación \\
\hline $\begin{array}{l}\text { Ray, Playcard-Augustin- } \\
\text { Fidèle (Abbé) }\end{array}$ & $\begin{array}{l}\text { Zoologie universelle et portative } \\
\text { ou Histoire naturelle de tous les } \\
\text { quadrupèdes }\end{array}$ & París & 1778 & $\begin{array}{l}\text { Historia } \\
\text { Natural }\end{array}$ \\
\hline $\begin{array}{l}\text { Réaumur, René-Antoine } \\
\text { Ferchault de (1683-1757) }\end{array}$ & $\begin{array}{l}\text { Mémoires pour servir à l'histoire } \\
\text { des insectes }\end{array}$ & París & $1734-42$ & $\begin{array}{l}\text { Historia } \\
\text { Natural }\end{array}$ \\
\hline $\begin{array}{l}\text { Renouard, Antoine- } \\
\text { Augustin, (1776-1853) }\end{array}$ & Idées d'un négociant & París & 1790 & $\begin{array}{l}\text { Economía } \\
\text { Comercio }\end{array}$ \\
\hline $\begin{array}{l}\text { Richer, Adrien (1720- } \\
\text { 1798) }\end{array}$ & $\begin{array}{l}\text { Nouvel abrégé chronologique de } \\
\text { l'histoire des empereurs }\end{array}$ & París & 1767 & Historia \\
\hline \multirow{2}{*}{$\begin{array}{l}\text { Richerand, Anthelme } \\
\text { Balthasar, baron (1779- } \\
\text { 1840) }\end{array}$} & $\begin{array}{l}\text { Nouveaux élémens de } \\
\text { physiologie }\end{array}$ & París & 1801 & Medicina \\
\hline & $\begin{array}{l}\text { Dissertation anatomico- } \\
\text { chirurgicale sur les fractures du } \\
\text { col du fémur. }\end{array}$ & París & 1799 & Medicina \\
\hline $\begin{array}{l}\text { Richter,Aug. Gottlieb } \\
\text { (1742-1812) }\end{array}$ & Traité des hernies & Colonia & 1779 & Medicina \\
\hline \multirow[b]{2}{*}{$\begin{array}{l}\text { Riquettí, Victor, (Marquis } \\
\text { de Mirabeau) (1715-1789) }\end{array}$} & $\begin{array}{l}\text { L'ami des hommes, ou, Traité de } \\
\text { la population }\end{array}$ & Avignon & $1756-60$ & Historia \\
\hline & $\begin{array}{l}\text { Philosophie rurale : ou Economie } \\
\text { générale et politique de } \\
\text { l'agriculture }\end{array}$ & $\begin{array}{l}\text { Ámsterda } \\
\mathrm{m}\end{array}$ & 1764 & $\begin{array}{l}\text { Economía } \\
\text { Comercio }\end{array}$ \\
\hline $\begin{array}{l}\text { Romé de L'Isle, De Jean- } \\
\text { Baptiste-Louis (1736- } \\
\text { 1790) }\end{array}$ & $\begin{array}{l}\text { Cristallographie ou description } \\
\text { des formes propres à tous les } \\
\text { corps du règne minéral }\end{array}$ & París & 1783 & $\begin{array}{l}\text { Historia } \\
\text { Natural }\end{array}$ \\
\hline $\begin{array}{l}\text { Römer, Johann Jacob } \\
\text { (1763-1819) }\end{array}$ & $\begin{array}{l}\text { Genera insectorum Linnaei et } \\
\text { Fabricii iconibus }\end{array}$ & $\begin{array}{l}\text { Winterth } \\
\text { ur }\end{array}$ & 1789 & $\begin{array}{l}\text { Historia } \\
\text { Natural }\end{array}$ \\
\hline Rottbll, Chistien Friis & $\begin{array}{l}\text { Descriptiones et icones rariorum } \\
\text { et pro maxima parte novarum } \\
\text { plantarum }\end{array}$ & $\begin{array}{l}\text { Copenag } \\
\text { ue }\end{array}$ & 1786 & Botánica \\
\hline $\begin{array}{l}\text { Rousseau, Jean-Baptiste } \\
\text { (1671-1741) }\end{array}$ & $\begin{array}{l}\text { L'hypocondre ou la femme qui ne } \\
\text { parle point, comédie }\end{array}$ & $\begin{array}{l}\text { Ámsterda } \\
\text { m }\end{array}$ & 1778 & $\begin{array}{l}\text { Lengua } \\
\text { Literatura }\end{array}$ \\
\hline $\begin{array}{l}\text { Rousset de Missy, Jean } \\
(1686-1762)\end{array}$ & $\begin{array}{l}\text { Observations sur l'origine, la } \\
\text { structure et la nature des vers-de- } \\
\text { mer. }\end{array}$ & La Haya & 1733 & $\begin{array}{l}\text { Historia } \\
\text { Natural }\end{array}$ \\
\hline $\begin{array}{l}\text { Rovière, Pierre (1599?- } \\
\text { 1623?) }\end{array}$ & $\begin{array}{l}\text { Historiæ Romanæ scriptores } \\
\text { Latini veteres }\end{array}$ & Ginebra & $\begin{array}{l}1609 y \\
1653 ?\end{array}$ & Historia \\
\hline
\end{tabular}




\begin{tabular}{|c|c|c|c|c|}
\hline \multirow{2}{*}{$\begin{array}{l}\text { Rozier, François-Benoît } \\
\text { (abbé), (1734-1793) }\end{array}$} & $\begin{array}{l}\text { Démonstrations élémentaires de } \\
\text { botanique }\end{array}$ & París & 1796 & Botánica \\
\hline & $\begin{array}{l}\text { journal de observations et } \\
\text { memoires sur le physique }\end{array}$ & París & $\begin{array}{l}1780- \\
1890 ?\end{array}$ & Ciencias \\
\hline $\begin{array}{l}\text { Rumpf, Georg Eberhard } \\
(1627-1702)\end{array}$ & Herbarium amboinense & $\begin{array}{l}\text { Ámsterda } \\
\mathrm{m}\end{array}$ & $\begin{array}{l}1741- \\
1750\end{array}$ & Botánica \\
\hline $\begin{array}{l}\text { Sage, Balthasar-George } \\
(1740-1824)\end{array}$ & $\begin{array}{l}\text { Analyse chimique et concordance } \\
\text { des trois règnes }\end{array}$ & París & 1786 & $\begin{array}{l}\text { Historia } \\
\text { Natural }\end{array}$ \\
\hline $\begin{array}{l}\text { Savary, Claude (1750- } \\
\text { 1780) }\end{array}$ & $\begin{array}{l}\text { Lettres sur la Grece faisant suite } \\
\text { de celles sur l'Egypte }\end{array}$ & París & 1788 & $\begin{array}{l}\text { Geografía/Viaj } \\
\text { es }\end{array}$ \\
\hline $\begin{array}{l}\text { Scapula, Johann } \\
\text { approximately (1540- } \\
1600)\end{array}$ & $\begin{array}{l}\text { Lexicon Graeco-latinum } \\
\text { locupletatum }\end{array}$ & $\begin{array}{l}\text { Ámsterda } \\
\mathrm{m}\end{array}$ & 1652 & $\begin{array}{l}\text { Lengua } \\
\text { Literartura }\end{array}$ \\
\hline $\begin{array}{l}\text { Scheuchzer, Johann } \\
\text { Jakob (1672-1733) }\end{array}$ & $\begin{array}{l}\text { Agrostographia, sive, Graminum, } \\
\text { juncorum, cyperorum }\end{array}$ & Zurich & 1775 & Agronomía \\
\hline \multirow{2}{*}{$\begin{array}{l}\text { Schrader, Heinrich } \\
\text { Adolph (1767-1836) }\end{array}$} & Nova genera plantarum & Leipzig & 1799 & Botánica \\
\hline & $\begin{array}{l}\text { Sertum Hannoveranum, seu } \\
\text { plantæ rariores, }\end{array}$ & Gottinga & $1795-97$ & Botánica \\
\hline $\begin{array}{l}\text { Seba, Albertus (1665- } \\
\text { 1736) }\end{array}$ & $\begin{array}{l}\text { Locupletissimi rerum naturalium } \\
\text { thesauri }\end{array}$ & $\begin{array}{l}\text { Ámsterda } \\
m\end{array}$ & $1734-65$ & $\begin{array}{l}\text { Historia } \\
\text { Natural }\end{array}$ \\
\hline Seidel, Johann Heinrich & $\begin{array}{l}\text { Synonymisches Verzeichnis aller } \\
\text { im Churfürstl. Orangengarten zu } \\
\text { Dresden }\end{array}$ & Dresden & 1799 & Medicina \\
\hline $\begin{array}{l}\text { Selle, Christian-Gottlieb } \\
\text { (1748-1800) }\end{array}$ & $\begin{array}{l}\text { Rudimenta Pyretologiae. } \\
\text { Methodicae }\end{array}$ & Berlín & 1789 & Ciencias \\
\hline \multirow[t]{2}{*}{$\begin{array}{l}\text { Senebier, Jean (1742- } \\
\text { 1809) }\end{array}$} & Physiologie végétale & Ginebra & 1800 & Botánica \\
\hline & $\begin{array}{l}\text { Sentimens d'un bon citoyen à la } \\
\text { lecture du résultat du Conseil } \\
\text { d'Etat }\end{array}$ & París & 1789 & $\begin{array}{l}\text { Economía } \\
\text { Comercio }\end{array}$ \\
\hline $\begin{array}{l}\text { Sheffield, John Holroyd, } \\
\text { Lord (1735-1821) }\end{array}$ & $\begin{array}{l}\text { Observations on the manufactures } \\
\text { trade and present state of Ireland }\end{array}$ & Londres & 1785 & $\begin{array}{l}\text { Economía } \\
\text { Comercio }\end{array}$ \\
\hline Sloane, Hans (1660-1753) & $\begin{array}{l}\text { a voyage to the Island } \\
\text { Madera,Barbadoes, Nieves,... }\end{array}$ & Londres & 1721 & $\begin{array}{l}\text { Geografía } \\
\text { Viajes }\end{array}$ \\
\hline $\begin{array}{l}\text { Smith, James Edward, } \\
\text { Sir (1759-1828) }\end{array}$ & Icones pictæ plantarum rariorum, & Londres & $1790-93$ & Botánica \\
\hline $\begin{array}{l}\text { Società Medica di } \\
\text { Emulazione di Genova. }\end{array}$ & $\begin{array}{l}\text { Memorie della Società Medica di } \\
\text { Emulazione di Genova }\end{array}$ & Génova & 1801 & Medicina \\
\hline $\begin{array}{l}\text { Societatis Regiae } \\
\text { Scientiarum Upsaliensis }\end{array}$ & $\begin{array}{l}\text { Nova acta Regiae Societatis } \\
\text { Scientiarum Upsaliensis }\end{array}$ & Upsala & 1795 & Ciencias \\
\hline $\begin{array}{l}\text { Société Médicale } \\
\text { d'Emulation. París }\end{array}$ & $\begin{array}{l}\text { Mémoires de la Société Médicale } \\
\text { d'Emulation }\end{array}$ & París & 1798 & Medicina \\
\hline $\begin{array}{l}\text { Sonnerat, Pierre (1748- } \\
\text { 1814) }\end{array}$ & $\begin{array}{l}\text { Voyage aux Indes Orientales et à } \\
\text { la Chine }\end{array}$ & París & 1782 & $\begin{array}{l}\text { Geografía } \\
\text { Viajes }\end{array}$ \\
\hline
\end{tabular}




\begin{tabular}{|c|c|c|c|c|}
\hline Sue, Pierre (1739-1816) & $\begin{array}{l}\text { Histoire du galvanisme et analyse } \\
\text { des différens ouvrages }\end{array}$ & París & 1802 & Medicina \\
\hline \multirow{3}{*}{ Swartz, Olof (1760-1818) } & $\begin{array}{l}\text { Observationes botanicae, quibus } \\
\text { plantae Indiae Occidentalis }\end{array}$ & Erlangen & 1791 & Botánica \\
\hline & $\begin{array}{l}\text { Flora indiae occidentalis aucta } \\
\text { atque illustrata }\end{array}$ & Erlangen & 1797 & Botánica \\
\hline & Icones plantarum incognitarum, & Erlangen & 1794 & Botánica \\
\hline $\begin{array}{l}\text { Swediaur, Franz (1748- } \\
\text { 1824) }\end{array}$ & $\begin{array}{l}\text { Traité complet sur les } \\
\text { symptomes, les effets de la nature } \\
\text { et le traitement des maladies } \\
\text { syphilitiques }\end{array}$ & París & 1801 & Medicina \\
\hline $\begin{array}{l}\text { Sydenham, Thomas } \\
\text { (1624-1689) }\end{array}$ & Médecine practique & París & 1774 & Medicina \\
\hline $\begin{array}{l}\text { Tasso, Torquato (1544- } \\
\text { 1595) }\end{array}$ & La Gerusalem liberata & París & 1792 & $\begin{array}{l}\text { Lengua } \\
\text { Literatura }\end{array}$ \\
\hline \multirow[t]{2}{*}{$\begin{array}{l}\text { Tessier, Alexandre-Henri } \\
\text { (1741-1837) }\end{array}$} & Traité des maladies des grains & París & 1783 & Medicina \\
\hline & $\begin{array}{l}\text { The merchant's and trader's vade } \\
\text { mecum }\end{array}$ & Londres & 1787 & $\begin{array}{l}\text { Economía } \\
\text { Comercio }\end{array}$ \\
\hline $\begin{array}{l}\text { The Royal kalender for } \\
1790\end{array}$ & & Londres & 1790 & $\begin{array}{l}\text { Bibliografías } \\
\text { Catálogos } \\
\text { Enciclopedias }\end{array}$ \\
\hline $\begin{array}{l}\text { Thevenot, Melchisédech, } \\
\text { (editor) }\end{array}$ & Veterum mathematicorum & París & 1693 & Ciencias \\
\hline \multirow{6}{*}{$\begin{array}{l}\text { Thunberg, Carl Peter } \\
(1743-1828)\end{array}$} & $\begin{array}{l}\text { Voyage en Afrique et en Asie, } \\
\text { principalement au Japon }\end{array}$ & París & 1794 & $\begin{array}{l}\text { Geografía } \\
\text { Viajes }\end{array}$ \\
\hline & Icones plantarum Japonicarum & Upsala & 1794 & Botánica \\
\hline & Prodromus plantarum Capensium & Upsala & 1794 & Botánica \\
\hline & $\begin{array}{l}\text { Flora Japonica, sistens plantas } \\
\text { insularum }\end{array}$ & Leipzig & 1784 & Botánica \\
\hline & $\begin{array}{l}\text { Voyages de C. P. Thunberg, au } \\
\text { Japon }\end{array}$ & París & 1796 & $\begin{array}{l}\text { Geografía } \\
\text { Viajes }\end{array}$ \\
\hline & $\begin{array}{l}\text { Voyage en Afrique et en Asie, } \\
\text { principalement au Japon, pendant } \\
\text { les années } 1770-1779: \text { servant de } \\
\text { suite au Voyage de D. Sparmann }\end{array}$ & París & 1787 & $\begin{array}{l}\text { Geografía } \\
\text { Viajes }\end{array}$ \\
\hline Toren, Olof (1718-1753) & Le Voyage de Mons & Milan & 1771 & $\begin{array}{l}\text { Geografía } \\
\text { Viajes }\end{array}$ \\
\hline \multirow[b]{2}{*}{$\begin{array}{l}\text { Tournefort, Joseph Pitton } \\
\text { de (1656-1708) }\end{array}$} & Abrégé des Elémens de botanique & Avignon & 1749 & Botánica \\
\hline & $\begin{array}{l}\text { Histoire des plantes qui naissent } \\
\text { aux environs de París }\end{array}$ & París & 1725 & Botánica \\
\hline \multirow[b]{2}{*}{$\begin{array}{l}\text { Vacca Berlinghieri, } \\
\text { Francesco (1732-1812) }\end{array}$} & Idee di fisiologia medica & Venecia & 1801 & Medicina \\
\hline & $\begin{array}{l}\text { Codice elementari di medicina } \\
\text { practica }\end{array}$ & Pisa & 1794 & Medicina \\
\hline
\end{tabular}




\begin{tabular}{|c|c|c|c|c|}
\hline & $\begin{array}{l}\text { Considerazioni intorno alle } \\
\text { malattie dette volgarmente } \\
\text { putride }\end{array}$ & Pisa & 1797 & Medicina \\
\hline & $\begin{array}{l}\text { Meditazioni sull'uomo malato e } \\
\text { sulla nuova dottrina medica di } \\
\text { Brown }\end{array}$ & Venecia & 1795 & Medicina \\
\hline $\begin{array}{l}\text { Vahl, Martinus } \\
\text { Hendricksen (1744-1804) }\end{array}$ & $\begin{array}{l}\text { Eclogae Americanae seu } \\
\text { Descriptiones plantarum } \\
\text { praesertim }\end{array}$ & $\begin{array}{l}\text { Copenag } \\
\text { ue }\end{array}$ & $1796-8$ & Botánica \\
\hline \multirow{2}{*}{$\begin{array}{l}\text { Vaillant, Sébastien (1669 } \\
\text { 1722) }\end{array}$} & Botanicon Parísiense & $\begin{array}{l}\text { Ámsterda } \\
\mathrm{m}\end{array}$ & 1727 & Botánica \\
\hline & Botanicon Parísiense & Leiden & 1727 & Botánica \\
\hline $\begin{array}{l}\text { Vallot, Jean Nicholas } \\
\text { (1771-1860), Réaumur, } \\
\text { René-Antoine Ferchault } \\
\text { de, (1683-1757). }\end{array}$ & $\begin{array}{l}\text { Concordance systématique, } \\
\text { servant de table de matières à } \\
\text { l'ouvrage de Réaumur, }\end{array}$ & París & 1802 & $\begin{array}{l}\text { Historia } \\
\text { Natural }\end{array}$ \\
\hline $\begin{array}{l}\text { Valmont de Bomare, } \\
\text { Jacques Christophe } \\
\text { (1731-1807) }\end{array}$ & $\begin{array}{l}\text { Dictionnaire raisonné universel } \\
\text { d'histoire naturelle }\end{array}$ & Lyon & 1800 & $\begin{array}{l}\text { Historia } \\
\text { Natural }\end{array}$ \\
\hline $\begin{array}{l}\text { Vatable, François , (- } \\
\text { 1547) }\end{array}$ & Biblia sacra, cum universis & París & 1729 & Religión \\
\hline $\begin{array}{l}\text { Ventenat,Etinne-Pierre } \\
(\mathbf{1 7 5 7 - 1 8 0 8 )}\end{array}$ & $\begin{array}{l}\text { Description des plantes nouvelles } \\
\text { et peu connues, cultivées dans le } \\
\text { jardin de J.M. Cels }\end{array}$ & París & 1800 & Botánica \\
\hline $\begin{array}{l}\text { Weikard, Melchior Adam } \\
(1742-1803)\end{array}$ & $\begin{array}{l}\text { Prospetto di un sistema più } \\
\text { semplice di medicina; ossia }\end{array}$ & Florencia & 1797 & Medicina \\
\hline
\end{tabular}

